S. Desmettre, A. Szimayer

Work effort, consumption, and portfolio selection: When the occupational choice matters 
(C) Fraunhofer-Institut für Techno- und Wirtschaftsmathematik ITWM 2010

ISSN 1434-9973

Bericht 188 (2010)

Alle Rechte vorbehalten. Ohne ausdrückliche schriftliche Genehmigung des Herausgebers ist es nicht gestattet, das Buch oder Teile daraus in irgendeiner Form durch Fotokopie, Mikrofilm oder andere Verfahren zu reproduzieren oder in eine für Maschinen, insbesondere Datenverarbeitungsanlagen, verwendbare Sprache zu übertragen. Dasselbe gilt für das Recht der öffentlichen Wiedergabe.

Warennamen werden ohne Gewährleistung der freien Verwendbarkeit benutzt.

Die Veröffentlichungen in der Berichtsreihe des Fraunhofer ITWM können bezogen werden über:

Fraunhofer-Institut für Techno- und Wirtschaftsmathematik ITWM Fraunhofer-Platz 1

67663 Kaiserslautern

Germany

Telefon: $\quad+49(0) 631 / 31600-0$

Telefax: $\quad+49(0) 631 / 31600-1099$

E-Mail: info@itwm.fraunhofer.de

Internet: www.itwm.fraunhofer.de 
Das Tätigkeitsfeld des Fraunhofer-Instituts für Techno- und Wirtschaftsmathematik ITWM umfasst anwendungsnahe Grundlagenforschung, angewandte Forschung sowie Beratung und kundenspezifische Lösungen auf allen Gebieten, die für Techno- und Wirtschaftsmathematik bedeutsam sind.

In der Reihe »Berichte des Fraunhofer ITWM « soll die Arbeit des Instituts kontinuierlich einer interessierten Öffentlichkeit in Industrie, Wirtschaft und Wissenschaft vorgestellt werden. Durch die enge Verzahnung mit dem Fachbereich Mathematik der Universität Kaiserslautern sowie durch zahlreiche Kooperationen mit internationalen Institutionen und Hochschulen in den Bereichen Ausbildung und Forschung ist ein großes Potenzial für Forschungsberichte vorhanden. In die Berichtreihe werden sowohl hervorragende Diplom- und Projektarbeiten und Dissertationen als auch Forschungsberichte der Institutsmitarbeiter und Institutsgäste zu aktuellen Fragen der Techno- und Wirtschaftsmathematik aufgenommen.

Darüber hinaus bietet die Reihe ein Forum für die Berichterstattung über die zahlreichen Kooperationsprojekte des Instituts mit Partnern aus Industrie und Wirtschaft.

Berichterstattung heißt hier Dokumentation des Transfers aktueller Ergebnisse aus mathematischer Forschungs- und Entwicklungsarbeit in industrielle Anwendungen und Softwareprodukte - und umgekehrt, denn Probleme der Praxis generieren neue interessante mathematische Fragestellungen.

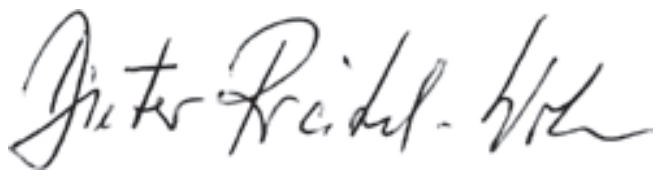

Prof. Dr. Dieter Prätzel-Wolters Institutsleiter

Kaiserslautern, im Juni 2001 



\title{
Work Effort, Consumption, and Portfolio Selection: When the Occupational Choice Matters
}

\author{
Sascha Desmettre* Alexander Szimayer ${ }^{\dagger}$
}

July 5, 2010

\begin{abstract}
We consider a highly-qualified individual with respect to her choice between two distinct career paths. She can choose between a mid-level management position in a large company and an executive position within a smaller listed company with the possibility to directly affect the company's share price. She invests in the financial market including the share of the smaller listed company. The utility maximizing strategy from consumption, investment, and work effort is derived in closed form for logarithmic utility. The power utility case is discussed as well. Conditions for the individual to pursue her career with the smaller listed company are obtained. The participation constraint is formulated in terms of the salary differential between the two positions. The smaller listed company can offer less salary. The salary shortfall is offset by the possibility to benefit from her work effort by acquiring own-company shares. This gives insight into aspects of optimal contract design. Our framework is applicable to the pharmaceutical and financial industry, and the IT sector.
\end{abstract}

2000 MSC Subject Classification: 49L20, 91B28, 93E20

Key Words: portfolio choice, work effort, consumption, occupational choice

*Department of Financial Mathematics, Fraunhofer ITWM, Fraunhofer-Platz 1, 67663 Kaiserslautern, Germany; Center for Mathematical and Computational Modelling and Department of Mathematics, University of Kaiserslautern, Germany. Email: sascha.desmettre@itwm.fraunhofer.de. This paper is part of the PhD thesis of Sascha Desmettre.

${ }^{\dagger}$ Faculty of Economics and Law, University of Bonn, Adenauerallee 24-42, 53113 Bonn, Germany. Email: szimayer@uni-bonn.de. 


\section{Introduction}

It is widely supported that the remuneration of managers should be linked to performance, see, e.g., Ross (1973), Jensen and Meckling (1976), Holmstrom (1979) and others, for the fundamentals of agency theory, and the summaries of Murphy (1999) and Core, Guay and Larcker (2003). In contrast to past research, we investigate the motivation for an individual to voluntarily performance-link her private wealth by acquiring shares in the own-company. We consider a highly-qualified individual with respect to her choice between two distinct career paths. She can choose between a midlevel management position in a large company and an executive position in a smaller listed company with the possibility to directly affect the company's share price. The individual is assumed to be utility maximizing, deriving utility from terminal wealth and intertemporal consumption, and negative utility (disutility or cost) from work effort. The investment opportunities include the share of the smaller listed company and thus the individual can capitalize on her work effort by investing in own-company shares. Taking up the mid-level management position with the large company is the outside option in our setting. The outside option rules out the possibility to affect the share price of the smaller company. The individual is characterized by two time preference parameters ( $\rho$, discount rate for utility from consumption, and $\tilde{\rho}$, discount rate for the disutility from work effort), and two work effectiveness parameters $(\kappa$, representing inverse work productivity, and $\alpha$, representing disutility stress).

First, we analyze the individuals optimal control problem under the assumption that she takes up the offer from the smaller listed company. The optimal investment strategy $\left(\pi^{\star}\right)$, consumption $\left(k^{\star}\right)$, and work effort $\left(\lambda^{\star}\right)$, respectively, are derived in closed form in the log-utility setting using stochastic control theory and the corresponding Hamilton-Jacobi-Bellman equations. We demonstrate that an executive with higher work effectiveness (quality) undertakes more work effort. Additionally, the broader constant relative risk aversion setting is explored. By imposing a sensible parameter restriction we are able to reduce the problem to a Riccati equation which we can solve in closed form. As second step, we identify conditions for the individual to work for the smaller listed company. The participation constraint is given in terms of the salary differential of the two job alternatives. In particular, we derive the minimal required salary $\delta^{\star}$ that needs to be offered by the smaller company to attract the individual and thereby characterize the 
participation constraint. In general, we find that a more talented individual requires a lower salary to be attracted to the smaller listed company. The salary shortfall is offset by the possibility to benefit from her work effort by acquiring shares of the company. This salary pattern can be observed in practice, e.g., in the pharmaceutical industry, the IT sector, and the financial industry. Other technical papers similarly concerned with dynamic principalagent models include Cadenillas, Cvitanic and Zapatero (2004), Desmettre, Gould and Szimayer (2010), Korn and Kraft (2008) and Ou-Yang (2003), for example.

The paper is organized as follows. Section 2 introduces the notation and terminology. In Section 3 the Hamilton-Jacobi-Bellman equations characterizing the utility and consumption maximization problem are derived, and closed-form solutions for the log-utility case are established. The power utility case is discussed as well. The results are illustrated in Section 4. Section 5 concludes and gives an outlook for future research. Technical proofs are in the Appendix.

\section{Notation and Setup}

We consider an individual endowed with given initial wealth. She manages here financial objectives by investing in the financial market and choosing her instantaneous consumption. The individual can also choose the level of work effort she applies.

\subsection{Financial Market}

First we specify the financial market. We are given a filtered probability space $\left(\Omega, \mathcal{F}, P,\left(\mathcal{F}_{t}\right)_{t \geq 0}\right)$ satisfying the usual hypothesis and large enough to support two independent standard Brownian motions, $W^{P}=\left(W_{t}^{P}\right)_{t \geq 0}$ and $W=\left(W_{t}\right)_{t \geq 0}$. The investment opportunities available are a money market account, a diversified market portfolio, and shares of a small listed company making a job offer to the individual.

The risk-free money market account has the price process $B=\left(B_{t}\right)_{t \geq 0}$, with dynamics

$$
\mathrm{d} B_{t}=r B_{t} \mathrm{~d} t, \quad B_{0}=1,
$$

where $r$ is the instantaneous risk-free rate of return, hence $B_{t}=e^{r t}$. 
The price process of the market portfolio, $P=\left(P_{t}\right)_{t \geq 0}$, follows the stochastic differential equation (SDE)

$$
\mathrm{d} P_{t}=P_{t}\left(\mu_{P} \mathrm{~d} t+\sigma_{P} \mathrm{~d} W_{t}^{P}\right), \quad P_{0} \in \mathbb{R}^{+},
$$

where $\mu_{P} \in \mathbb{R}$ and $\sigma_{P}>0$ are respectively the expected return rate and volatility of the market portfolio. The corresponding Sharpe ratio is then $\lambda_{P}=\left(\mu_{P}-r\right) / \sigma_{P}$.

The company's stock price process, $S^{u}=\left(S_{t}^{u}\right)_{t \geq 0}$, is a controlled diffusion with SDE

$$
\mathrm{d} S_{t}^{u}=S_{t}^{u}\left(\left[r+\lambda_{t} \sigma\right] \mathrm{d} t+\beta\left[\frac{\mathrm{d} P_{t}}{P_{t}}-r \mathrm{~d} t\right]+\sigma \mathrm{d} W_{t}\right), \quad S_{0}^{u} \in \mathbb{R}^{+},
$$

where $\mu=r+\lambda \sigma$ is the company's expected return rate in excess of the beta-adjusted market portfolio's expected excess return rate (i.e. the expected return compensation for non-systematic risk), $\sigma$ is the company's non-systematic volatility, and $\lambda=\left(\lambda_{t}\right)_{t \geq 0}$ is a control process collected in the control vector process $u$ that will be specified below.

\subsection{Controls and Wealth Process}

The individual is endowed with the initial wealth $V_{0}>0$. She receives an instantaneous salary proportional to her current wealth at a relative rate $\delta$. For an exogenously given time horizon, $T>0$, the individual seeks to maximize her total utility by controlling the portfolio holdings, consumption, and work effort.

The portfolio is determined by a self-financing trading strategy given by the bivariate control process $\pi=\left(\pi^{P}, \pi^{S}\right)$, where $\pi^{P}=\left(\pi_{t}^{P}\right)_{t \geq 0}$ is the fraction of wealth invested in the market portfolio and $\pi^{S}=\left(\pi_{t}^{S}\right)_{t \geq 0}$ is the fraction of wealth invested in the company's stock. The remainder in the risk-free account, that is, the strategy is self-financing. The individual consumes instantaneously at the relative rate $k=\left(k_{t}\right)_{t \geq 0}$ proportional to the wealth $V_{t}^{\pi}$ at time $t$, where $k_{t} \geq 0$, leading to a total consumption rate $k_{t} V_{t}^{\pi}$. Further, she influences the small company's stock price dynamics by choice of the control strategy $\lambda=\left(\lambda_{t}\right)_{t \geq 0}$, which is specified to be associated with work effort. The control strategy can be conceptualized as deriving from the individual's corporate investment. For example, identifying and initiating positive net present value projects. Value is added if $\mu=r+\lambda \sigma$ is greater than $r$, indicating excess return compensation for non-systematic risk. To ensure sensible 
solutions we require $\lambda \geq 0$, which effectively bars her from destroying company value $(\lambda<0)$ and potentially profiting by shorting the company's stock. All controls are collected in the vector process $u=\left(\pi^{P}, \pi^{S}, k, \lambda\right)$.

For a fixed salary rate $\delta$, initial wealth $V_{0}>0$, and a control strategy $u$, the wealth process, $V^{u}=\left(V_{t}^{u}\right)_{t \geq 0}$, with starting value $V_{0}^{u}=V_{0}$ is given by

$$
\mathrm{d} V_{t}^{u}=V_{t}^{u}\left(\left[1-\pi_{t}^{P}-\pi_{t}^{S}\right] \frac{\mathrm{d} B_{t}}{B_{t}}+\pi_{t}^{P} \frac{\mathrm{d} P_{t}}{P_{t}}+\pi_{t}^{S} \frac{\mathrm{d} S_{t}^{u}}{S_{t}^{u}}+\delta \mathrm{d} t-k_{t} \mathrm{~d} t\right), t \geq 0 .
$$

The above equation can be rewritten as follows

$$
\begin{aligned}
& \mathrm{d} V_{t}^{u}=V_{t}^{u}\left(\left[r+\delta-k_{t}+\left(\pi_{t}^{P}+\beta \pi_{t}^{S}\right) \lambda_{P} \sigma_{P}+\pi_{t}^{S} \lambda_{t} \sigma\right] \mathrm{d} t\right. \\
&\left.+\left[\pi_{t}^{P}+\beta \pi_{t}^{S}\right] \sigma_{P} \mathrm{~d} W_{t}^{P}+\pi_{t}^{S} \sigma \mathrm{d} W_{t}\right), t \geq 0 .
\end{aligned}
$$

\subsection{Stochastic Control Problem}

The individual is assumed to maximize the expected value of the terminal utility of her wealth for time horizon $T$, subject to some utility function $U_{1}$ and her consumption rate over the time period $[t, T]$, subject to some utility function $U_{2}$. The disutility for work effort is quantified by the cost function $C$. Both utility functions and the cost function will be specified when deriving closed-form solutions.

Assuming control of the company's stock price behavior $\lambda$ is determined exogenously and comes at zero cost, the individual's optimal investment and consumption decision is then described by

$$
\widehat{\Phi}(t, v)=\sup _{(\pi, k) \in \Pi(t, v)} \mathbb{E}^{t, v}\left[U_{1}\left(V_{T}^{(\pi, k)}\right)+\int_{t}^{T} U_{2}\left(s, V_{s}^{(\pi, k)}, k_{s}\right) \mathrm{d} s\right],
$$

for $(t, v) \in[0, T] \times \mathbb{R}^{+}$, where $\Pi(t, v)$ denotes the set of all admissible portfolio processes $(\pi, k)$ at time $t$ corresponding to portfolio value (i.e. wealth) $v=V_{t}>0$ (see for example Korn and Korn (2001)), $U_{1}$ and $U_{2}$ are utility functions, and $\mathbb{E}^{t, v}$ denotes the expectation conditional on $t$ and $v$.

The optimal investment and consumption control decision including work effort is then the solution of

$$
\Phi(t, v)=\sup _{u \in A(t, v)} \mathbb{E}^{t, v}\left[U_{1}\left(V_{T}^{u}\right)+\int_{t}^{T} U_{2}\left(s, V_{s}^{u}, k_{s}\right) \mathrm{d} s-\int_{t}^{T} C\left(s, V_{s}^{u}, \lambda_{s}\right) \mathrm{d} s\right],
$$


for $(t, v) \in[0, T] \times \mathbb{R}^{+}$. The set of admissible strategies for the maximization $A(t, v)$ problem is made precise in the following definition.

Definition 2.1 Fix $(t, v) \in[0, T] \times \mathbb{R}^{+}$, then $u=\left(\pi^{P}, \pi^{S}, k, \lambda\right)$ is in the set of admissible strategies $A(t, v)$, if and only if $u$ is an $\left\{\mathcal{F}_{s} ; t \leq s \leq T\right\}$ predictable processes, such that

(i) the stock price equation

$$
\mathrm{d} S_{s}^{u}=S_{s}^{u}\left(\left[r+\lambda_{s} \sigma\right] \mathrm{d} s+\beta\left[\frac{\mathrm{d} P_{s}}{P_{s}}-r \mathrm{~d} s\right]+\sigma \mathrm{d} W_{s}\right),
$$

with initial condition $S_{t}^{u} \in \mathbb{R}^{+}$admits a non-negative solution and

$$
\int_{t}^{T}\left(S_{s}^{u}\right)^{2}\left(\sigma^{2}+\beta^{2} \sigma_{P}^{2}\right) \mathrm{d} s<\infty \quad P-a . s .
$$

(ii) the wealth equation

$$
\mathrm{d} V_{s}^{u}=V_{s}^{u}\left(\left[1-\pi_{s}^{P}-\pi_{s}^{S}\right] \frac{\mathrm{d} B_{s}}{B_{s}}+\pi_{s}^{P} \frac{\mathrm{d} P_{s}}{P_{s}}+\pi_{s}^{S} \frac{\mathrm{d} S_{s}^{u}}{S_{s}^{u}}+\delta \mathrm{d} s-k_{s} \mathrm{~d} s\right),
$$

with initial condition $V_{t}^{u}=v$ has a unique non-negative solution and

$$
\int_{t}^{T}\left(V_{s}^{u}\right)^{2}\left(\left(\left[\pi_{s}^{P}+\beta \pi_{s}^{S}\right] \sigma_{P}\right)^{2}+\left(\pi_{s}^{S} \sigma\right)^{2}\right) \mathrm{d} s<\infty \quad P-\text { a.s. } ;
$$

(iii) and the utility of wealth and consumption, and the disutility of control satisfy

$$
\mathbb{E}\left[U_{1}\left(V_{T}^{u}\right)^{-}+\int_{t}^{T} U_{2}\left(s, V_{s}^{u}, k_{s}\right)^{-} \mathrm{d} s+\int_{t}^{T} C\left(s, V_{s}^{u}, \lambda_{s}\right) \mathrm{d} s\right]<\infty .
$$

\subsection{Outside Option}

The individual can choose between two job offers at $t=0$. As an alternative to taking on the executive position with the company with share price $S^{u}$, she can pursue her outside option and decide to work for a large company in a mid-management position paying a salary at rate $\widehat{\delta}$. In the latter case she cannot affect the stock price process any longer and hence $\widehat{\lambda}=0$. The classical optimal investment and consumption decision applies.

Assume that portfolio process follows Eq. (5) where we set $\delta=\widehat{\delta}$ and $\lambda=\widehat{\lambda}=0$. Then the optimal investment decision problem in Equation (6) determines the value of the outside option $\widehat{\Phi}\left(0, V_{0}\right)$ at time $t=0$ for initial wealth $V_{0}>0$. 


\section{Optimal Strategies}

In this section we use stochastic control techniques to derive closed-form solutions to the control problem in (7). Our main focus is placed on the log utility specification for utility from terminal wealth and consumption and disutility that is a power function of work effort applied. In addition, we also discuss the general constant relative risk aversion specification.

\subsection{Hamilton-Jacobi-Bellman Equation}

Having formulated the optimal investment and control decision problem including consumption with respect to the parameter set $u=(\pi, k, \lambda)$ as given by (7), we can write down the corresponding Hamilton-Jacobi-Bellman equation. Note that we formulate this equation with respect to a general utility functions $U_{1}$ and $U_{2}$ and a general cost function $C$. For $(t, v) \in[0, T) \times \mathbb{R}^{+}$ we have

$$
\frac{\partial \Phi}{\partial t}(t, v)+\sup _{u \in \mathcal{U}}\left[\left(L^{u} \Phi\right)(t, v)+U_{2}(t, v, k)-C(t, v, \lambda)\right]=0,
$$

with terminal condition $\Phi(T, v)=U_{1}(v)$, for $v \in \mathbb{R}^{+}$, where $\mathcal{U}=\mathbb{R}^{2} \times[0, \infty)^{2}$ and the differential operator $L^{u}$ is defined by

$$
\begin{aligned}
& \left(L^{u} g\right)(t, v)= \\
& \frac{\partial g}{\partial v}(t, v) v\left(r+\delta+\pi^{S}(t, v) \lambda(t, v) \sigma+\left[\pi^{P}(t, v)+\beta \pi^{S}(t, v)\right] \lambda_{P} \sigma_{P}-k(t, v)\right) \\
& +\frac{1}{2} \frac{\partial^{2} g}{\partial v^{2}}(t, v) v^{2}\left(\left[\pi^{S}(t, v) \sigma\right]^{2}+\left[\pi^{P}(t, v) \sigma_{P}+\beta \pi^{S}(t, v) \sigma_{P}\right]^{2}\right) .
\end{aligned}
$$

Potential maximizers $\pi^{P^{\star}}, \pi^{S^{\star}}, k^{\star}$ and $\lambda^{\star}$ of the HJB (8) can be calculated by establishing the first order conditions:

$$
\begin{aligned}
& \pi^{P^{\star}}(t, v)=-\frac{\lambda_{P}}{v \sigma^{P}} \frac{\Phi_{v}(t, v)}{\Phi_{v v}(t, v)}-\beta \pi^{S^{\star}}(t, v), \\
& \pi^{S^{\star}}(t, v)=-\frac{\lambda^{\star}(t, v)}{v \sigma} \frac{\Phi_{v}(t, v)}{\Phi_{v v}(t, v)},
\end{aligned}
$$

and $\lambda^{\star}$ is the solution of the implicit equation

$$
\lambda \frac{\Phi_{v}^{2}(t, v)}{\Phi_{v v}(t, v)}+\frac{\partial C}{\partial \lambda}(t, v, \lambda)=0, \quad \text { for all }(t, v) \in[0, T] \times \mathbb{R}^{+}
$$


where we have already used (10) to simplify the equation, and $k^{\star}$ is the solution of the equation

$$
\frac{\partial U_{2}}{\partial k}(t, v, k)-v \Phi_{v}(t, v)=0 .
$$

Substituting the maximizers (10) in the HJB (8) yields:

$$
\begin{aligned}
\Phi_{t}(t, v)+ & \Phi_{v}(t, v) v\left(r+\delta-k^{\star}(t, v)\right)-\frac{1}{2}\left(\lambda^{\star}(t, v)\right)^{2} \frac{\Phi_{v}^{2}(t, v)}{\Phi_{v v}(t, v)} \\
& -\frac{1}{2} \lambda_{P}^{2} \frac{\Phi_{v}^{2}(t, v)}{\Phi_{v v}(t, v)}+U_{2}\left(t, k^{\star}(t, v)\right)-C\left(t, v, \lambda^{\star}(t, v)\right)=0 .
\end{aligned}
$$

In the following we solve (13) with particular choices for the utility and disutility functions.

\subsection{Closed-Form Solution for the Log-Utility Case}

We specify the utility functions to be of log-utility type, belonging to the constant relative risk aversion class. The utility function of the final wealth $U_{1}$ is

$$
U_{1}(v)=K \log (v), \quad \text { for } v \in \mathbb{R}^{+},
$$

for a constant $K>0$, the utility function of consumption $U_{2}$ is

$$
U_{2}(t, k, v)=e^{-\rho t} \log (v k), \quad \text { for }(t, v, k) \in[0, T] \times \mathbb{R}^{+} \times \mathbb{R}_{0}^{+},
$$

where $\rho \in \mathbb{R}$ parametrizes the time preference, and the cost function of work effort $C$ is

$$
C(t, v, \lambda)=e^{-\tilde{\rho} t} \kappa \frac{\lambda^{\alpha}}{\alpha}, \quad \text { for }(t, v, \lambda) \in[0, T] \times \mathbb{R}^{+} \times \mathbb{R}_{0}^{+},
$$

where $\kappa>0$ and $\alpha>2$ are the individual's work effectiveness parameters, respectively termed 'inverse work productivity' and 'disutility stress', and $\tilde{\rho} \in \mathbb{R}$ is a time preference parameter. The constant $\kappa$ directly relates the her work effort disutility to the quality of his control decision as indicated by the non-systematic Sharpe ratio $\lambda$, and $\alpha$ indicates how rapidly her work effort disutility will rise for the sake of an improved $\lambda$. The requirement $\alpha>2$ is a consequence of our set-up that ensures the executive's disutility grows with work effort, i.e. $\lambda$, at a rate that offsets (at some level of $\lambda$ ) the rate 
of her utility gain due to the flow-on from her work effort to the value of his own-company stockholding; this becomes evident with derivation of the solution to (7). A higher quality individual is able to achieve a given $\lambda$ with lower disutility, and is able to improve $\lambda$ with lower incremental disutility. That is, higher individual quality (i.e. higher work effectiveness) is implied by lower values of $\kappa$ and $\alpha$.

For the remainder of the paper we assume that the optimal investment and control problem (7) admits a value function $\Phi \in C^{1,2}$. To guarantee that the candidates we will derive for the executive's optimal investment and control strategy (i.e. the choices for own-company stockholding, market portfolio holding and non-systematic Sharpe ratio) and value function are indeed optimal, we have to consider a more restrictive class of admissible strategies as follows.

Definition 3.1 Fix $(t, v) \in[0, T] \times \mathbb{R}^{+}$. Then by $A^{\prime}(t, v)$ we denote the set of admissible strategies $u \in A^{\prime}(t, v)$, such that $u \in A(t, v)$ and

$$
\mathbb{E}\left[\int_{t}^{T}\left(\pi_{s}^{P}+\beta \pi_{s}^{S}\right)^{2}\left(\sigma_{P}\right)^{2}+\left(\pi_{s}^{S} \sigma\right)^{2} \mathrm{~d} s\right]<\infty
$$

Restating the optimal investment and control problem:

$$
\Phi(t, v)=\sup _{u \in A^{\prime}(t, v)} \mathbb{E}^{t, v}\left[U_{1}\left(V_{T}^{u}\right)+\int_{t}^{T} U_{2}\left(s, V_{s}^{u}, k_{s}\right) \mathrm{d} s-\int_{t}^{T} C\left(s, V_{s}^{u}, \lambda_{s}\right) \mathrm{d} s\right],
$$

for $(t, v) \in[0, T] \times \mathbb{R}^{+}$.

A closed-form solution is obtained for the optimal investment and control problem in (18) using the utility and disutility functions (14), (15) and (16).

Theorem 3.1 The full solution of the maximization problem (18) can be summarized by the strategy

$$
\begin{array}{ll}
\pi^{P^{\star}}(t, v)=\frac{\lambda_{P}}{\sigma_{P}}-\beta \pi^{S^{\star}}(t, v), & \pi^{S^{\star}}(t, v)=\frac{\lambda^{\star}(t, v)}{\sigma}, \\
\lambda^{\star}(t, v)=\left(\frac{e^{\tilde{\rho} t}}{\kappa} f(t)\right)^{\frac{1}{\alpha-2}}, & k^{\star}(t, v)=\frac{e^{-\rho t}}{f(t)},
\end{array}
$$

and value function

$$
\Phi(t, v)=f(t) \log (v)+g(t),
$$


with

$$
f(t)= \begin{cases}K+\frac{e^{-\rho t}-e^{-\rho T}}{\rho}, & \text { for } \rho \neq 0 \\ K+T-t, & \text { for } \rho=0\end{cases}
$$

and

$$
\begin{aligned}
g(t)= & \left(r+\delta+\frac{1}{2} \lambda_{P}^{2}\right) \int_{t}^{T} f(s) \mathrm{d} s+\frac{\alpha-2}{2 \alpha} \int_{t}^{T}\left(\frac{e^{\tilde{\rho} s}}{\kappa}\right)^{\frac{2}{\alpha-2}} f(s)^{\frac{\alpha}{\alpha-2}} \mathrm{~d} s \\
& -\int_{t}^{T}(1+\rho s) e^{-\rho s} \mathrm{~d} s-\int_{t}^{T} e^{-\rho s} \log (f(s)) \mathrm{d} s .
\end{aligned}
$$

Proof. First observe that a function $F$ of the form $F(\lambda)=a \lambda^{2}-b \lambda^{\alpha}$, $\lambda \geq 0$, for given constants $a, b>0$ and $\alpha>2$, has a unique maximizer $\lambda^{\star}$ and maximized value $F\left(\lambda^{\star}\right)$ given by

$$
\lambda^{\star}=\left(\frac{2 a}{\alpha b}\right)^{\frac{1}{\alpha-2}}, \quad \text { and } \quad F\left(\lambda^{\star}\right)=(\alpha-2) \alpha^{-\frac{\alpha}{\alpha-2}} 2^{\frac{2}{\alpha-2}} a^{\frac{\alpha}{\alpha-2}} b^{-\frac{2}{\alpha-2}} .
$$

Using this insight, the first order condition for $\lambda^{\star}$ in $(11)$ is now solved. Set

$$
a=\frac{1}{2} \frac{\Phi_{v}^{2}}{-\Phi_{v v}}, \quad \text { and } \quad b=e^{-\tilde{\rho} t} \frac{\kappa}{\alpha},
$$

then (21) gives

$$
\lambda^{\star}=\left(\frac{e^{\tilde{\rho} t}}{\kappa} \frac{\Phi_{v}^{2}}{-\Phi_{v v}}\right)^{\frac{1}{\alpha-2}}, \text { and } F\left(\lambda^{\star}\right)=\frac{\alpha-2}{2 \alpha}\left(\frac{e^{\tilde{\rho} t}}{\kappa}\right)^{\frac{2}{\alpha-2}}\left(\frac{\Phi_{v}^{2}}{-\Phi_{v v}}\right)^{\frac{\alpha}{\alpha-2}} .
$$

Having specified the utility function $U_{2}$ of the consumption rate as $U_{2}(t, v, k)=$ $e^{-\rho t} \log (v k)$, we can also solve the first order condition for the optimal consumption rate. Equation (12) then gives:

$$
k^{\star}=\frac{e^{-\rho t}}{v \Phi_{v}} .
$$

Substituting $\lambda^{\star}$ and $k^{\star}$ in equation (13) we get:

$$
\begin{aligned}
0= & \Phi_{t}+\Phi_{v} v(r+\delta)+\frac{1}{2} \lambda_{P}^{2} \frac{\Phi_{v}^{2}}{-\Phi_{v v}}+\frac{\alpha-2}{2 \alpha}\left(\frac{e^{\tilde{\rho} t}}{\kappa}\right)^{\frac{2}{\alpha-2}}\left(\frac{\Phi_{v}^{2}}{-\Phi_{v v}}\right)^{\frac{\alpha}{\alpha-2}} \\
& -e^{-\rho t}-\rho t e^{-\rho t}-e^{-\rho t} \log \left(\Phi_{v}\right) .
\end{aligned}
$$


Using the ansatz $\Phi(t, v)=\log (v) f(t)+g(t)$ with $f(T)=K$ and $g(T)=0$ results in

$$
\begin{aligned}
& \Phi_{t}=\log (v) \dot{f}(t)+\dot{g}(t), \quad \Phi_{v}=\frac{1}{v} f(t), \quad \Phi_{v v}=-\frac{1}{v^{2}} f(t), \text { and } \\
& \Phi(T, v)=K \log (v)=U_{1}(v) .
\end{aligned}
$$

Then (24) reduces to

$$
\begin{aligned}
0= & \log (v) \dot{f}(t)+\dot{g}(t)+f(t)\left(r+\delta+\frac{1}{2} \lambda_{P}^{2}\right)+\frac{\alpha-2}{2 \alpha}\left(\frac{e^{\tilde{\rho} t}}{\kappa}\right)^{\frac{2}{\alpha-2}} f(t)^{\frac{\alpha}{\alpha-2}} \\
& -e^{-\rho t}-\rho t e^{-\rho t}+e^{-\rho t} \log (v)-e^{-\rho t} \log (f(t)) .
\end{aligned}
$$

Taking the derivative of this equation w.r.t. $v$ gives:

$$
\frac{1}{v} \dot{f}(t)+\frac{1}{v} e^{-\rho t}=0 \Longleftrightarrow \dot{f}(t)=-e^{-\rho t} .
$$

Using the condition $f(T)=K$ we then get by integration

$$
f(t)= \begin{cases}K+\frac{e^{-\rho t}-e^{-\rho T}}{\rho}, & \text { for } \rho \neq 0 \\ K+T-t, & \text { for } \rho=0\end{cases}
$$

Following the derivation of $f$ we can eliminate the $\log (v)$ in $(25)$

$$
\begin{aligned}
-\dot{g}(t)= & f(t)\left(r+\delta+\frac{1}{2} \lambda_{P}^{2}\right)+\frac{\alpha-2}{2 \alpha}\left(\frac{e^{\tilde{\rho} t}}{\kappa}\right)^{\frac{2}{\alpha-2}} f(t)^{\frac{\alpha}{\alpha-2}} \\
& -e^{-\rho t}-\rho t e^{-\rho t}-e^{-\rho t} \log (f(t)), \text { and } g(T)=0 .
\end{aligned}
$$

Equation (26) can now be solved by simple integration:

$$
\begin{aligned}
g(t)= & \left(r+\delta+\frac{1}{2} \lambda_{P}^{2}\right) \int_{t}^{T} f(s) \mathrm{d} s+\frac{\alpha-2}{2 \alpha} \int_{t}^{T}\left(\frac{e^{\tilde{\rho} s}}{\kappa}\right)^{\frac{2}{\alpha-2}} f(s)^{\frac{\alpha}{\alpha-2}} \mathrm{~d} s \\
& -\int_{t}^{T}(1+\rho s) e^{-\rho s} \mathrm{~d} s-\int_{t}^{T} e^{-\rho s} \log f(s) \mathrm{d} s,
\end{aligned}
$$

where $f(t)$ is given as above.

Combining the results for the functions $f$ and $g$ we then get the claimed result 
for the value function. Noting that $\Phi_{v} / \Phi_{v v}=-v$ and using the first order conditions in (10) establishes the claimed optimal strategies $\pi^{P^{\star}}$ and $\pi^{S^{\star}}$. Finally noting that $\Phi_{v}^{2} / \Phi_{v v}=-f(t)$ and using the solved first order condition (22), we get the desired result for the optimal sharpe ratio $\lambda^{\star}$ and plugging in $v \Phi_{v}=f$ in (23) we get the claimed result for the optimal consumption rate $k^{\star}$. The claimed optimal investment and control choices are deterministic and the optimal consumption rate are continuous on a compact support, so they are uniformly bounded implying $u^{\star}=\left(\pi^{S^{\star}}, \pi^{P^{\star}}, \lambda^{\star}, k^{\star}\right) \in A^{\prime}(t, v)$.

Remark 3.1 The expression for $g$ in Theorem 3.1 can be partially calculated fairly explicitly. For $\rho \neq 0$ we obtain

$$
\begin{aligned}
g(t)= & \left(r+\delta+\frac{1}{2} \lambda_{P}^{2}\right)\left(K[T-t]+\frac{1}{\rho^{2}}\left[e^{-\rho t}-e^{-\rho T}(1+\rho[T-t])\right]\right) \\
& -\frac{1}{\rho}\left(e^{-\rho t}-e^{-\rho T}\right)-t e^{-\rho t}+T e^{-\rho T}+K \log (K) \\
& -\log \left(K+\frac{1}{\rho}\left[e^{-\rho t}-e^{-\rho T}\right]\right)\left(K+\frac{1}{\rho}\left[e^{-\rho t}-e^{-\rho T}\right]\right) \\
& +\frac{\alpha-2}{2 \alpha} \int_{t}^{T}\left(\frac{e^{\tilde{\rho} s}}{\kappa}\right)^{\frac{2}{\alpha-2}} f(s)^{\frac{\alpha}{\alpha-2}} \mathrm{~d} s .
\end{aligned}
$$

The integral in the last line can in general not be computed in closed form. However, it can be expressed as a hypergeometric function. For $\rho=0$, the function $g$ can be obtained by continuity in $\rho$, i.e. fix $t$ and then compute the limit for $\rho \rightarrow 0$.

The solutions of the maximization problems given in Theorem 3.1 are candidates for the optimal investment and control choices as well as for the optimal consumption rate for the problem in (18). In the following theorem we verify that under sufficient assumptions these solutions are indeed optimal.

Theorem 3.2 (Verification) Let $\kappa>0$ and $\alpha>2$. Assume the executive's utility function of wealth, the utility function of the consumption rate as well as the cost function are given by (14), (15) and (16). Then the candidates given in (19) and (20) are the optimal investment and control strategy (i.e. own-company stockholding, market portfolio holding and non-systematic Sharpe ratio strategy), the optimal consumption rate and value function of the optimal control problem (18). 
Proof. Define the performance functional of our optimal investment, consumption and control decision by

$$
J^{\prime}(t, v ; \pi, k, \lambda):=\mathbb{E}^{t, v}\left[U_{1}\left(V_{T}^{u}\right)+\int_{t}^{T} U_{2}\left(s, V_{s}^{u}, k_{s}\right) \mathrm{d} s-\int_{t}^{T} C\left(s, V_{s}^{u}, \lambda_{s}\right) \mathrm{d} s\right] .
$$

Our candidates are optimal if we have

$$
\begin{aligned}
& J^{\prime}\left(t, v ; \pi^{\star}, k^{\star}, \lambda^{\star}\right)=\Phi(t, v) \text { and } \\
& J^{\prime}(t, v ; \pi, k, \lambda) \leq \Phi(t, v), \text { for all }(\pi, k, \lambda) \in A_{1}^{\prime}(t, v) .
\end{aligned}
$$

Let $u \in A_{1}^{\prime}(t, v)$. Since $\Phi \in C^{1,2}$, we obtain by Ito's formula:

$$
\begin{aligned}
\Phi( & \left.T, V_{T}^{u}\right)+\int_{t}^{T} e^{-\rho s} \log \left(V_{s}^{u} k_{s}\right) \mathrm{d} s-\int_{t}^{T} e^{-\tilde{\rho} s} \kappa \frac{\lambda_{s}^{\alpha}}{\alpha} \mathrm{d} s \\
= & \Phi(t, v)+\int_{t}^{T}\left(\Phi_{t}\left(s, V_{s}^{u}\right)+e^{-\rho s} \log \left(V_{s}^{u} k_{s}\right)-e^{-\tilde{\rho} s} \kappa \frac{\lambda_{s}^{\alpha}}{\alpha}\right) \mathrm{d} s \\
& +\int_{t}^{T} \Phi_{v}\left(s, V_{s}^{u}\right) V_{s}^{u}\left(r+\delta-k_{s}+\left[\pi_{s}^{P}+\beta \pi_{s}^{S}\right] \lambda_{P} \sigma_{P}+\pi_{s}^{S} \lambda_{s} \sigma\right) \mathrm{d} s \\
& +\frac{1}{2} \int_{t}^{T} \Phi_{v v}\left(s, V_{s}^{u}\right)\left(V_{s}^{u}\right)^{2}\left(\left[\left(\pi_{s}^{P}+\beta \pi_{s}^{S}\right) \sigma_{P}\right]^{2}+\left[\pi_{s}^{S} \sigma\right]^{2}\right) \mathrm{d} s \\
& +\int_{t}^{T} \Phi_{v}\left(s, V_{s}^{u}\right) V_{s}^{u}\left(\pi_{s}^{P}+\beta \pi_{s}^{S}\right) \sigma_{P} \mathrm{~d} W_{s}^{P}+\int_{t}^{T} \Phi_{v}\left(s, V_{s}^{u}\right) V_{s}^{u} \pi_{s}^{S} \sigma \mathrm{d} W_{s} .
\end{aligned}
$$

First, we investigate the optimal control $u^{\star}=\left(\pi^{P^{\star}}, \pi^{S^{\star}}, \lambda^{\star}, k^{\star}\right)$ given in (19). To show that the local martingale component in (29) vanishes in expectation we check the sufficient integrability condition

$$
\mathbb{E}\left[\int_{t}^{T}\left(\Phi_{v}\left(s, V_{s}^{u^{\star}}\right) V_{s}^{u^{\star}}\right)^{2}\left(\left[\pi_{s}^{P^{\star}}+\beta \pi_{s}^{S^{\star}}\right]^{2} \sigma_{P}^{2}+\left[\pi_{s}^{S^{\star}}\right]^{2} \sigma^{2}\right) \mathrm{d} s\right]<\infty .
$$

From (19) and (20) we obtain

$$
\left(\Phi_{v}\left(s, V_{s}^{u^{\star}}\right) V_{s}^{u^{\star}}\right)^{2}\left(\left[\pi_{s}^{P^{\star}}+\beta \pi_{s}^{S^{\star}}\right]^{2} \sigma_{P}^{2}+\left[\pi_{s}^{S^{\star}}\right]^{2} \sigma^{2}\right)=(f(s))^{2}\left(\lambda_{P}^{2}+\left[\lambda^{\star}(s)\right]^{2}\right) .
$$

Now, $f$ and $\lambda^{\star}$ are deterministic continuous functions on the compact $[0, T]$, and thus the above expression is uniformly bounded. Accordingly the expectation in (30) is finite, and the Wiener integrals in (29) vanish in expectation. 
Furthermore, $\Phi$ satisfies the HJB equation (8) implying

$$
\begin{aligned}
0= & \Phi_{v}\left(s, V_{s}^{u^{\star}}\right) V_{s}^{u^{\star}}\left(r+\delta-k_{s}+\left[\pi_{s}^{P^{\star}}+\beta \pi_{s}^{S^{\star}}\right] \lambda_{P} \sigma_{P}+\pi_{s}^{S^{\star}} \lambda_{s}^{\star} \sigma\right) \\
& +\frac{1}{2} \Phi_{v v}\left(s, V_{s}^{u^{\star}}\right)\left(V_{s}^{u^{\star}}\right)^{2}\left(\left[\left(\pi_{s}^{P^{\star}}+\beta \pi_{s}^{S^{\star}}\right) \sigma_{P}\right]^{2}+\left[\pi_{s}^{S^{\star}} \sigma\right]^{2}\right) \\
& +\Phi_{t}\left(s, V_{s}^{u^{\star}}\right)+e^{-\rho s} \log \left(V_{s}^{u^{\star}} k_{s}^{\star}\right)-e^{-\tilde{\rho} s} \kappa \frac{\left(\lambda_{s}^{\star}\right)^{\alpha}}{\alpha}, \quad \text { for } t \leq s \leq T .
\end{aligned}
$$

Then, using that $\Phi(T, v)=U_{1}(v)$ the expectation of $(29)$ is:

$$
\begin{aligned}
\Phi(t, v) & =\mathbb{E}^{t, v}\left[\Phi\left(T, V_{T}^{u^{\star}}\right)+\int_{t}^{T} e^{-\rho s} \log \left(V_{s}^{u^{\star}} k_{s}^{\star}\right) \mathrm{d} s-\int_{t}^{T} e^{-\tilde{\rho} s} \kappa \frac{\left(\lambda_{s}^{\star}\right)^{\alpha}}{\alpha} \mathrm{d} s\right] \\
& \left.=\mathbb{E}^{t, v}\left[U_{1}\left(V_{T}^{u^{\star}}\right)\right)+\int_{t}^{T} U_{2}\left(s, V_{s}^{u^{\star}}, k_{s}^{\star}\right) \mathrm{d} s-\int_{t}^{T} C\left(s, V_{s}^{u^{\star}}, \lambda_{s}^{\star}\right) \mathrm{d} s\right] \\
& =J^{\prime}\left(t, v ; \pi^{\star}, \lambda^{\star}, k^{\star}\right) .
\end{aligned}
$$

Thus we have verified the first part of (28).

Next, fix $u \in A^{\prime}(t, v)$. By the HJB equation (8), we have

$$
\begin{aligned}
0 \geq & \Phi_{t}\left(s, V_{s}^{u}\right)+\Phi_{v}\left(s, V_{s}^{u}\right) V_{s}^{u}\left(r+\delta-k_{s}+\left[\pi_{s}^{P}+\beta \pi_{s}^{S}\right] \lambda_{P} \sigma_{P}+\pi_{s}^{S} \lambda_{s} \sigma\right) \\
& +\frac{1}{2} \Phi_{v v}\left(s, V_{s}^{u}\right)\left(V_{s}^{u}\right)^{2}\left(\left[\left(\pi_{s}^{P}+\beta \pi_{s}^{S}\right) \sigma_{P}\right]^{2}+\left[\pi_{s}^{S} \sigma\right]^{2}\right) \\
& +e^{-\rho s} \log \left(V_{s}^{u} k_{s}\right)-e^{-\tilde{\rho} s} \kappa \frac{\lambda_{s}^{\alpha}}{\alpha}, \quad \text { for } t \leq s \leq T
\end{aligned}
$$

Substituting this in (29) and recalling that $\Phi_{v}(t, v)=\frac{1}{v} f(t)$ we get:

$$
\begin{aligned}
& \Phi\left(T, V_{T}^{\pi}\right)+\int_{t}^{T} e^{-\rho s} \log \left(V_{s}^{u} k_{s}\right) \mathrm{d} s-\int_{t}^{T} e^{-\tilde{\rho} s} \kappa \frac{\lambda_{s}^{\alpha}}{\alpha} \mathrm{d} s \\
& \left.\leq \Phi(t, v)+\int_{t}^{T} f(s)\right)\left(\pi_{s}^{P}+\beta \pi_{s}^{S}\right) \sigma_{P} \mathrm{~d} W_{s}^{P}+\int_{t}^{T} f(s) \pi_{s}^{S} \sigma \mathrm{d} W_{s} .
\end{aligned}
$$

Taking the expectation on both sides and keeping in mind that $\Phi(T, v)=$ 
$U_{1}(v)$ then yields

$$
\begin{aligned}
J^{\prime}(t, v ; \pi, \lambda, k) \\
\left.\quad=\mathbb{E}^{t, v}\left[U_{1}\left(V_{T}^{u}\right)\right)+\int_{t}^{T} U_{2}\left(s, V_{s}^{u}, k_{s}\right) \mathrm{d} s-\int_{t}^{T} C\left(s, V_{s}^{u}, \lambda_{s}\right) \mathrm{d} s\right] \\
\quad=\mathbb{E}^{t, v}\left[\Phi\left(T, V_{T}^{u}\right)+\int_{t}^{T} e^{-\rho s} \log \left(V_{s}^{u} k_{s}\right) \mathrm{d} s-\int_{t}^{T} e^{-\tilde{\rho} s} \kappa \frac{\lambda_{s}^{\alpha}}{\alpha} \mathrm{d} s\right] \\
\quad \leq \Phi(t, v)+\underbrace{\mathbb{E}^{t, v}\left[\int_{t}^{T} f(s)\left(\pi_{s}^{P}+\beta \pi_{s}^{S}\right) \sigma_{P} \mathrm{~d} W_{s}^{P}+\int_{t}^{T} f(s) \pi_{s}^{S} \sigma \mathrm{d} W_{s}\right]}_{=0, \text { by }(17)} .
\end{aligned}
$$

The Wiener integral vanishes in expectation since the corresponding integrand is square integrable, since $f$ is uniformly bounded and (17).

\subsection{Participation Constraint for the Log-Utility Case}

The optimal strategies in Theorem 3.1 and Theorem 3.2 above apply in case the individual decides to work for the smaller listed company. However, she has the opportunity to take up an outside option, that is, working for a larger company in a mid-level management position. The outside option offers a contract that differs in the salary rate and foregoes the possibility of controlling the stock price of the smaller listed company. Next, we calculate the value of the outside option and derive the participation constraint.

The outside option pays a salary rate $\widehat{\delta}$. Taking on the position results in the loss of the ability to influence the stock price of the smaller listed company and therefore $\widehat{\lambda}=0$. She can invest in the financial market. The classical optimal investment and consumption decision applies. For the remainder of this subsection we assume that the portfolio process follows Eq. (5) where we set $\delta=\widehat{\delta}$ and $\lambda=\widehat{\lambda}=0$. Then the optimal investment decision problem in Equation (6) determines the value of the outside option $\widehat{\Phi}\left(0, V_{0}\right)$ at time $t=0$ for initial wealth $V_{0}>0$. The solution $\widehat{\Phi}$ can be obtained as a simplification of the results in Theorem 3.1 and Theorem 3.2, i.e. $\widehat{\Phi}(t, v)=\widehat{f}(t) \log (v)+\widehat{g}(t)$ with

$$
\widehat{f}(t)= \begin{cases}K+\frac{e^{-\rho t}-e^{-\rho T}}{\rho}, & \text { for } \rho \neq 0 \\ K+T-t, & \text { for } \rho=0\end{cases}
$$


and

$$
\begin{aligned}
\widehat{g}(t)= & \left(r+\widehat{\delta}+\frac{1}{2} \lambda_{P}^{2}\right) \int_{t}^{T} \widehat{f}(s) \mathrm{d} s \\
& -\int_{t}^{T}(1+\rho s) e^{-\rho s} \mathrm{~d} s-\int_{t}^{T} e^{-\rho s} \log (\widehat{f}(s)) \mathrm{d} s .
\end{aligned}
$$

Observe that $\widehat{f}=f$ and

$$
g(t)-\widehat{g}(t)=(\delta-\widehat{\delta}) \int_{t}^{T} f(s) \mathrm{d} s+\frac{\alpha-2}{2 \alpha} \int_{t}^{T}\left(\frac{e^{\tilde{\rho} s}}{\kappa}\right)^{\frac{2}{\alpha-2}} f(s)^{\frac{\alpha}{\alpha-2}} \mathrm{~d} s .
$$

Based on the discussion above we can state the participation constraint.

Theorem 3.3 Let $\widehat{\delta}$ be the salary rate of the outside option. Then the value of the outside option is the solution $\widehat{\Phi}$ to optimal investment and consumption problem in (6) with dynamics (5) where we set $\delta=\widehat{\delta}$ and $\lambda=\widehat{\lambda}=0$. The participation constraint for the individual is

$$
\delta \geq \widehat{\delta}-\frac{(\alpha-2)}{2 \alpha} \frac{\int_{0}^{T}\left(\frac{e^{\tilde{\rho} t}}{\kappa}\right)^{\frac{2}{\alpha-2}} f(t)^{\frac{\alpha}{\alpha-2}} \mathrm{~d} t}{\int_{0}^{T} f(t) \mathrm{d} t}
$$

where $f$ is given in Theorem 3.1.

Proof. The value function is of the form $\widehat{\Phi}=\widehat{f}(t) \log (v)+\widehat{g}(t)$ with $\widehat{f}=f$ and $\widehat{g}-g$ given in (31). Then we have of course $\Phi(t, v)-\widehat{\Phi}(t, v)=g(t)-\widehat{g}(t)$ and the participation constraint $\Phi\left(0, V_{0}\right) \geq \widehat{\Phi}\left(0, V_{0}\right)$ follows as stated in (32).

\subsection{Discussion of the Power-Utility Case}

In this subsection, we derive a closed-form solution for the case of power utility. In particular, we specify a constant relative risk aversion utilitydisutility set-up. For the relative risk aversion parameter $\gamma>1$, the utility function of the final wealth $U_{1}$ is

$$
U_{1}(v)=\frac{v^{1-\gamma}}{1-\gamma}, \text { for } \gamma>1
$$


the utility function of the consumption $U_{2}$ is

$$
U_{2}(k, v)=\frac{(v k)^{1-\gamma}}{1-\gamma}, \quad \text { for } \gamma>1
$$

and the disutility of control (i.e. work effort) $C$ is

$$
C(v, \lambda)=\kappa v^{1-\gamma} \frac{\lambda^{\alpha}}{\alpha}, \quad \text { for } \gamma>1,
$$

where $\kappa>0$ and $\alpha>2$ are as in the log-utility part.

Compared to the log-utility setup we have made the simplifying assumption that utility from consumption in (34) and the cost from work effort in (35) are not depending on time, see (15) and (16) for time preferences in the log-utility setup. These assumption enable us to obtain a tractable formulation of the problem. However, we require a further structural assumption linking the cost function parameter $\alpha$ to the relative risk aversion $\gamma$. The following condition is assumed to hold:

$$
\alpha=2 \gamma+2
$$

Condition (36) enables us to reduce an ODE of inhomogeneous Bernoulli type that appears in the HJB equation to an ODE of Riccati type, which we are able to solve in closed-form. This restriction is however not counterintuitive. A more risk averse individual is implicitly assumed to be more sensitive towards work. When focusing on the optimal work effort $\lambda^{\star}$ as a main result we can rely on Desmettre et al. (2010) discussing a related framework although without consumption and salary. Their results indicate that $\lambda^{\star}$ decreases with increasing risk aversion as well as with increasing disutility stress. So by relating those two parameters via (36) we do not change the qualitative behavior of the optimal work effort.

Analogously to the log-utility case, to guarantee indeed the optimality of the candidates we will derive for the executive's optimal investment and control strategy and value function, we consider again a more restrictive class of admissible strategies as follows.

Definition 3.2 Fix $(t, v) \in[0, T] \times \mathbb{R}^{+}$. Then for $\gamma>1$, we denote by $A_{\gamma}^{\prime}(t, v)$ the set of admissible strategies $u \in A_{\gamma}^{\prime}(t, v)$, such that $u \in A_{\gamma}(t, v)$ 
and

$$
\begin{aligned}
& \int_{t}^{T}\left(\pi_{s}^{P}+\beta \pi_{u}^{S}\right)^{4}\left(\sigma^{P}\right)^{4}+\left(\pi_{u}^{S} \sigma\right)^{4} \mathrm{~d} u \leq C_{1}<\infty, \quad \text { for some } C_{1} \in \mathbb{R}_{0}^{+}, \\
& \int_{t}^{T} \pi_{u}^{S} \sigma \lambda_{u} \mathrm{~d} u \geq C_{2}>-\infty, \quad \text { for some } C_{2} \in \mathbb{R}_{0}^{+} \\
& \int_{t}^{T} k_{u} \mathrm{~d} u \leq C_{3}<\infty, \quad \text { for some } C_{3} \in \mathbb{R}_{0}^{+}
\end{aligned}
$$

Theorem 3.4 (The power-utility case: $\gamma>1$ ) Suppose that the relative risk aversion parameter $\gamma$ and the disutility stress parameter $\alpha$ are connected via the relation (36), then the full solution of the maximization problem (18) can be summarized by the strategy

$$
\begin{aligned}
\pi^{P^{\star}}(t, v) & =\frac{\mu^{P}-r}{\gamma\left(\sigma^{P}\right)^{2}}-\beta \pi^{S^{\star}}(t, v), \quad \pi^{S^{\star}}(t, v)=\frac{\lambda^{\star}(t, v)}{\gamma \sigma^{\star}\left(t, v, \lambda^{\star}(t, v)\right)}, \\
\lambda^{\star}(t, v) & =\left(\frac{1}{\kappa \gamma} f(t)\right)^{\frac{1}{2 \gamma}}, \quad k^{\star}(t, v)=(f(t))^{-\frac{1}{\gamma}},
\end{aligned}
$$

and value function

$$
\Phi(t, v)=\frac{v^{1-\gamma}}{1-\gamma} f(t)
$$

where

$$
f(t)=\left(\frac{2\left(1-g_{P}\right) \sqrt{C_{0}}}{2 \sqrt{C_{0}} e^{-2 \sqrt{C_{0}}(T-t)}+\left(1-g_{P}\right)\left(e^{-2 \sqrt{C_{0}}(T-t)}-1\right)}+g_{P}\right)^{-\gamma},
$$

with

$$
C_{0}=\frac{(\gamma-1)^{2}}{4 \gamma^{2}}\left(r+\delta+\frac{1}{2} \frac{\lambda_{P}^{2}}{\gamma}\right)^{2}-\frac{\kappa}{2} \frac{(1-\gamma)}{(1+\gamma)}\left(\frac{1}{\kappa \gamma}\right)^{\frac{\gamma+1}{\gamma}}
$$

and

$$
g_{P}=-\frac{1-\gamma}{2 \gamma}\left(r+\delta+\frac{1}{2} \frac{\lambda_{P}^{2}}{\gamma}\right)+\sqrt{C_{0}}
$$


Proof. First observe that a function $F$ of the form $F(\lambda)=a \lambda^{2}-b \lambda^{\alpha}$, $\lambda \geq 0$, for given constants $a, b>0$ and $\alpha>2$, has a unique maximizer $\lambda^{\star}$ and maximized value $F\left(\lambda^{\star}\right)$ given by

$$
\lambda^{\star}=\left(\frac{2 a}{\alpha b}\right)^{\frac{1}{\alpha-2}}, \quad \text { and } \quad F\left(\lambda^{\star}\right)=(\alpha-2) \alpha^{-\frac{\alpha}{\alpha-2}} 2^{\frac{2}{\alpha-2}} a^{\frac{\alpha}{\alpha-2}} b^{-\frac{2}{\alpha-2}} .
$$

Using this insight the first order condition for $\lambda^{\star}$ in (11) is now solved. Set

$$
a=\frac{1}{2} \frac{\Phi_{v}^{2}}{-\Phi_{v v}}, \quad \text { and } \quad b=\frac{\kappa}{\alpha} v^{1-\gamma}
$$

then (45) gives

$$
\lambda^{\star}=\left(\frac{1}{\kappa v^{1-\gamma}} \frac{\Phi_{v}^{2}}{-\Phi_{v v}}\right)^{\frac{1}{\alpha-2}}, \quad F\left(\lambda^{\star}\right)=\frac{\alpha-2}{2 \alpha}\left(\kappa v^{1-\gamma}\right)^{-\frac{2}{\alpha-2}}\left(\frac{\Phi_{v}^{2}}{-\Phi_{v v}}\right)^{\frac{\alpha}{\alpha-2}} .
$$

Having specified the utility function as $U_{2}\left(t, k_{t}\right)=\frac{(v k)^{1-\gamma}}{1-\gamma}$, the first order condition (12) for the optimal consumption rate becomes:

$$
k^{\star}=\frac{1}{v}\left(\Phi_{v}\right)^{-\frac{1}{\gamma}} .
$$

Substituting $\lambda^{\star}$ and $k^{\star}$ in (13) then yields:

$$
\begin{aligned}
0= & \Phi_{t}+\Phi_{v} v(r+\delta)+\frac{1}{2} \frac{\Phi_{v}^{2}}{-\Phi_{v v}}\left(\lambda^{P}\right)^{2} \\
& +\frac{\alpha-2}{2 \alpha}\left(\kappa v^{1-\gamma}\right)^{-\frac{2}{\alpha-2}}\left(\frac{\Phi_{v}^{2}}{-\Phi_{v v}}\right)^{\frac{\alpha}{\alpha-2}}+\frac{\gamma}{1-\gamma}\left(\Phi_{v}\right)^{\frac{\gamma-1}{\gamma}} .
\end{aligned}
$$

Using the separation ansatz $\Phi(t, v)=f(t) \frac{v^{1-\gamma}}{1-\gamma}$ results in

$$
\Phi_{t}=\dot{f} \frac{v^{1-\gamma}}{1-\gamma}, \quad \Phi_{v}=f v^{-\gamma}, \quad \Phi_{v v}=-\gamma f v^{-\gamma-1}, \quad \text { and } \quad f(T)=1
$$

Thus (46) becomes

$$
\begin{aligned}
0=\dot{f} \frac{v^{1-\gamma}}{1-\gamma} & +f v^{1-\gamma}(r+\delta)+\frac{1}{2} \frac{f v^{1-\gamma}}{\gamma}\left(\lambda^{P}\right)^{2} \\
& +\frac{\alpha-2}{2 \alpha}\left(\kappa v^{1-\gamma}\right)^{-\frac{2}{\alpha-2}}\left(\frac{f v^{1-\gamma}}{\gamma}\right)^{\frac{\alpha}{\alpha-2}}+\frac{\gamma}{1-\gamma} v^{1-\gamma} f^{\frac{\gamma-1}{\gamma}} .
\end{aligned}
$$


Dividing by $\frac{v^{1-\gamma}}{1-\gamma}$ and then defining

$$
\begin{aligned}
& a_{1}=(1-\gamma)\left(r+\delta+\frac{1}{2} \frac{\lambda_{P}^{2}}{\gamma}\right), a_{n}=(1-\gamma) \frac{\kappa}{2} \frac{\alpha-2}{\alpha}\left(\frac{1}{\kappa \gamma}\right)^{\frac{\alpha}{\alpha-2}}, \\
& a_{m}=\gamma, \quad n=\frac{\alpha}{\alpha-2}, \quad \text { and } \quad m=\frac{\gamma-1}{\gamma} .
\end{aligned}
$$

results in an ordinary differential equation of the form

$$
\dot{f}+a_{1} f+a_{n} f^{n}+a_{m} f^{m}=0 .
$$

The ansatz $g=f^{1-n}$ yields $\dot{g}=\frac{1-n}{f^{n}} \dot{f}$ and thus

$$
\dot{g}+a_{1}(1-n) g+a_{m}(1-n) g^{\frac{m-n}{1-n}}=-a_{n}(1-n) \quad, \quad g(T)=1 .
$$

Using (36), i.e. $\alpha=2+2 \gamma$, and plugging in the coefficients in (48) we obtain the following ODE of Riccati type

$$
\dot{g}-\frac{1-\gamma}{\gamma}\left(r+\delta+\frac{1}{2} \frac{\lambda_{P}^{2}}{\gamma}\right) g-g^{2}=\frac{\kappa}{2} \frac{1-\gamma}{1+\gamma}\left(\frac{1}{\kappa \gamma}\right)^{\frac{\gamma+1}{\gamma}} .
$$

This ODE can be solved if we know a particular solution $g_{P}$, since then we can reduce this ODE by using the standard ansatz

$$
h=1 /\left(g-g_{P}\right)
$$

to the following linear form:

$$
\dot{h}+\left[2 g_{P}+\frac{\gamma-1}{\gamma}\left(r+\delta+\frac{1}{2} \frac{\lambda_{P}^{2}}{\gamma}\right)\right] h+1=0, \quad h(T)=\frac{1}{1-g_{P}} .
$$

This equation can now be solved by variation of constants. A nonnegative particular solution of $(50)$ is

$$
\begin{aligned}
g_{P}= & -\frac{1-\gamma}{2 \gamma}\left(r+\delta+\frac{1}{2} \frac{\lambda_{P}^{2}}{\gamma}\right) \\
& +\sqrt{\frac{(\gamma-1)^{2}}{4 \gamma^{2}}\left(r+\delta+\frac{1}{2} \frac{\lambda_{P}^{2}}{\gamma}\right)^{2}-\frac{\kappa}{2} \frac{(1-\gamma)}{(1+\gamma)}\left(\frac{1}{\kappa \gamma}\right)^{\frac{\gamma+1}{\gamma}}}
\end{aligned}
$$


which means that we have to solve the following inhomogeneous linear ODE

$$
\dot{h}+\left[2 \sqrt{\frac{(\gamma-1)^{2}}{4 \gamma^{2}}\left(r+\delta+\frac{1}{2} \frac{\lambda_{P}^{2}}{\gamma}\right)^{2}-\frac{\kappa}{2} \frac{(1-\gamma)}{(1+\gamma)}\left(\frac{1}{\kappa \gamma}\right)^{\frac{\gamma+1}{\gamma}}}\right] h+1=0 .
$$

Now applying variation of constants and using that $h(T)=1 /\left(1-g_{P}\right)$, the solution of this ODE is

$$
h(t)=\frac{1}{1-g_{P}} e^{2 \sqrt{C_{0}}(T-t)}+\frac{1}{2 \sqrt{C_{0}}}\left(e^{2 \sqrt{C_{0}}(T-t)}-1\right),
$$

where

$$
C_{0}=\frac{(\gamma-1)^{2}}{4 \gamma^{2}}\left(r+\delta+\frac{1}{2} \frac{\lambda_{P}^{2}}{\gamma}\right)^{2}-\frac{\kappa}{2} \frac{(1-\gamma)}{(1+\gamma)}\left(\frac{1}{\kappa \gamma}\right)^{\frac{\gamma+1}{\gamma}}
$$

Transforming the result back to the function $f$ we get

$$
f(t)=\left(g_{P}+\frac{2\left(1-g_{P}\right) \sqrt{C_{0}}}{2 \sqrt{C_{0}} e^{2 \sqrt{C_{0}}(T-t)}+\left(1-g_{P}\right)\left(e^{2 \sqrt{C_{0}}(T-t)}-1\right)}\right)^{-\gamma} .
$$

Using the representations (47) we get

$$
\lambda^{\star}(t, v)=\left(\frac{1}{\kappa v^{1-\gamma}} \frac{\Phi_{v}^{2}}{-\Phi_{v v}}\right)^{\frac{1}{\alpha-2}}=\left(\frac{1}{\kappa \gamma} f(t)\right)^{\frac{1}{\alpha-2}}=\left(\frac{1}{\kappa \gamma} f(t)\right)^{\frac{1}{2 \gamma}},
$$

and

$$
\begin{aligned}
& \pi^{P^{\star}}(t, v)=-\frac{\left(\mu^{P}-r\right)}{v\left(\sigma^{P}\right)^{2}} \frac{\Phi_{v}(t, v)}{\Phi_{v v}(t, v)}-\beta \pi^{S^{\star}}(t, v)=\frac{\mu^{P}-r}{\gamma\left(\sigma^{P}\right)^{2}}-\beta \pi^{S^{\star}}(t, v), \\
& \pi^{S^{\star}}(t, v)=-\frac{\lambda^{\star}(t, v)}{v \sigma^{\star}\left(t, v, \lambda^{\star}(t, v)\right)} \frac{\Phi_{v}(t, v)}{\Phi_{v v}(t, v)}=\frac{\lambda^{\star}(t, v)}{\gamma \sigma^{\star}\left(t, v, \lambda^{\star}(t, v)\right)},
\end{aligned}
$$

as well as

$$
k^{\star}(t, v)=\frac{1}{v}\left(\phi_{v}(t, v)\right)^{-\frac{1}{\gamma}}=\frac{1}{v}\left(f(t) v^{-\gamma}\right)^{-\frac{1}{\gamma}}=(f(t))^{-\frac{1}{\gamma}} .
$$

And the proof is finished. 
Remark 3.2 Establishing the solution is based on the function $f$ in (49). The transformation $g=f^{-1 / \gamma}$ is applied and requires $f$ to be nonnegative. Accordingly, the function $g$ satisfies the Riccati ODE in (50) and lives also on $\mathbb{R}^{+}$. As a solution strategy we identifying a particular solution $g_{P}$. This works for $\gamma>1$, since then $g_{P}>0$, i.e. the particular solution is in the region where $g$ is specified on. However, the solution strategy brakes down for $0<\gamma<1$. Then we would have $g_{P}<0$ and this candidate is not an admissible solution. This explains why we cannot provide a solution for the case $0<\gamma<1$, at least, with our methods at hand.

Again, we need to show that the candidates derived in Theorem (3.4) are indeed optimal. This is done in the following verification theorem. The proof is provided in the Appendix.

Theorem 3.5 (Verification Result for the Case $\gamma>1$ ) Let $\kappa>0$ and $\alpha>2$ and $\alpha=2 \gamma+2$. Assume the utility function of wealth, the utility function of the consumption rate and the disutility function are given by (33), (34) and (35), respectively. Then the candidates given via (40) - (44) are the optimal investment and control strategy (i.e. own-company stockholding, market portfolio holding and non-systematic Sharpe ratio strategy), the optimal consumption rate and value function of the optimal control problem (18) for the case $\gamma>1$.

\section{Discussion and Implications of Results}

The previous section established results on the optimal behavior of the individual and derived the participation constraint, i.e. conditions for the her to accept the offer by the smaller listed company. In the following we discuss the results by investigating the sensitivities of the optimal strategies and the participation constraint when varying model parameters.

\subsection{Optimal Work Effort}

Theorems 3.1 and 3.2 indicate the individual's maximized utility and associated optimal behavior in terms of personal portfolio selection, consumption and work effort decision, given that she accepts to job offer by the smaller listed company, all subject to the log utility set-up. We now investigate the sensitivity of the optimal work effort to variations of the risk aversion and 
work effectiveness characteristics and time preference. Note that the portfolio selection and consumption are in line with standard results in the log utility setup and are here of limited interest.

The individual is characterized by the work effectiveness parameters work productivity $(1 / \kappa$, with $\kappa>0)$, and disutility stress $(\alpha>2)$ and the time preferences of consumption from work effort $(\rho \in \mathbb{R})$ and disutility $(\tilde{\rho} \in$ $\mathbb{R})$, respectively. To produce results that have relativity to a base-level of work effort, as indicated by a base-level non-systematic Sharpe ratio control decision $\lambda_{0}>0$, the disutility $C$ given by (16) is reparameterized to

$$
C(t, v, \lambda)=e^{-\tilde{\rho} t} \frac{\tilde{\kappa}}{\alpha}\left(\frac{\lambda}{\lambda_{0}}\right)^{\alpha}, \quad \text { for } \lambda \geq 0, \quad \gamma>0,
$$

and the utility of wealth $U_{1}$ and the utility of consumption $U_{2}$ remain unchanged.

The individual's optimal work effort for the new disutility parametrization is $\lambda^{\star}(t, v)=\lambda_{0}^{\frac{\alpha}{\alpha-2}}\left(\frac{e^{\tilde{\rho} t}}{\tilde{\kappa}} f(t)\right)^{\frac{1}{\alpha-2}}$ (see Theorem 3.1 for the optimal choice under the original parametrization). Assuming that the inverse work productivity satisfies $1 / \tilde{\kappa}>\lambda_{0}^{-2} e^{|\tilde{\rho}| T} / K$ we guarantee that the optimal work effort $\lambda^{\star}$ is not less than the base level $\lambda_{0}$, i.e. $\lambda^{\star} \geq \lambda_{0}>0$. If not stated otherwise, the default values for the parameters are $\alpha=5,1 / \tilde{\kappa}=1000, r=0.05, \lambda_{P}=0.20$, $\lambda_{0}=0.10, \rho=0.10, \tilde{\rho}=-0.10, K=1, \widehat{\delta}=0.20$, and $T=10$.

The individual's optimal work effort choice is positively related to her work productivity and negatively related to her disutility stress. This result is illustrated by Figures 1 and 2, which graph the optimal work effort $\lambda^{\star}$ versus time $t$ and work productivity $1 / \tilde{\kappa}$ and, time $t$ and disutility stress $\alpha$, respectively. Both figures indicate that the individual's optimal work effort is negatively related to time, i.e. $\lambda^{\star}$ is decreasing over time. The individual spends in general more work effort at the beginning of the time horizon. Note that the monotonicity of the optimal work effort depends on the sign of $\rho$, see discussion of Figure 4 below.

Figure 3 shows the optimal work effort choice $\lambda^{\star}$ w.r.t. the time preference of consumption $\rho$ and time $t$. The figure indicates that with increasing time the optimal work effort decreases as already observed above. This implies that the individual is more productive at the beginning of her career path. The optimal work effort is also decreasing for increasing time preference of consumption $\rho$. An individual which has a higher consumption preference will deliver a lower work effort, especially at the beginning of the time horizon. 
Figure 4 graphs the optimal work effort choice $\lambda^{\star}$ w.r.t. the time preference of disutility $\tilde{\rho}$ and time $t$. The optimal work effort is positively related to the time preference of work related disutility $\tilde{\rho}$, i.e. with increasing value of $\tilde{\rho}$ the individual is becoming more productive and delivers a higher level of the optimal work effort indicating a reasonable behavior: The higher the cost for spending work effort the lower is the optimal work effort. Note that positive values of $\tilde{\rho}$ are associated with work effort becoming cheaper over time. For this parameter set, we first observe over time an increase of work effort and then a decrease at the end of the time horizon. However, typically we expect $\tilde{\rho}$ to be negative, i.e., work effort becomes more expensive with the passing of time.

\subsection{Participation Constraint}

The participation constraint is given in Theorem 3.3. Denote $\delta^{\star}$ the minimal salary rate such that the participation constraint holds, i.e. $\delta^{\star}=\inf \{\delta \in \mathbb{R}$ : $\delta$ satisfies (32) $\}$. Taking account of the reparametrization gives

$$
\delta^{\star}=\left\{\begin{array}{l}
\delta_{0}-\frac{(\alpha-2)}{2 \alpha} \lambda_{0}^{\frac{2 \alpha}{\alpha-2}} \frac{\int_{0}^{T}\left(\frac{e^{\tilde{\rho} s}}{\tilde{\kappa}}\right)^{\frac{2}{\alpha-2}} f(s)^{\frac{\alpha}{\alpha-2}} \mathrm{~d} s}{K T+\frac{1}{\rho^{2}}\left[1-e^{-\rho T}(1+\rho T)\right]}, \text { for } \rho \neq 0, \\
\delta_{0}-\frac{(\alpha-2)}{2 \alpha} \lambda_{0}^{\frac{2 \alpha}{\alpha-2}} \frac{\int_{0}^{T}\left(\frac{e^{\tilde{\rho} s}}{\tilde{\kappa}}\right)^{\frac{2}{\alpha-2}} f(s)^{\frac{\alpha}{\alpha-2}} \mathrm{~d} s}{K T+\frac{1}{2} T^{2}}, \text { for } \rho=0 .
\end{array}\right.
$$

Now, $\alpha>2$ by assumption and $f>0$ by Theorem 3.1. And the minimal salary rate of the smaller listed company that is satisfying the participation constraint is always below the salary rate of the outside option, i.e. $\delta^{\star}<\delta$. The salary rate discount can be explained by the fact that the smaller company is offering in return for the reduced salary the possibility to affect the share price by work effort and thereby to increase the utility derived from the individual's investment. In the following we investigate the minimal required salary rate $\delta^{\star}$ depending on the individual's parameters (work productivity $1 / \tilde{\kappa}$, disutility stress $\alpha$, time preference of consumption $\rho$ and time preference for work effort $\tilde{\rho}$ ) to characterize individuals that are attracted by an offer of the smaller listed company.

Figure 5 displays the minimal required salary rate $\delta^{\star}$ w.r.t. disutility stress $\alpha$ and work productivity $1 / \tilde{\kappa}$. The minimal required salary rate is 
decreasing with increasing work productivity and increasing with increasing disutility stress. This means that a more productive individual is willing to accept a lower salary rate because she can compensate the loss of utility by the ability to improve the unsystematic Sharpe ratio $\lambda$. On the other hand, an individual with a higher disutility stress requires a higher salary rate to accept the contract from the smaller listed company.

The effect of the time preferences is shown in Figure 6. The required minimal salary rate $\delta^{\star}$ is graphed against the time preference of consumption $\rho$ and the time preference of disutility from work effort $\tilde{\rho}$, respectively. Increasing the time preference parameter for consumption increases the minimal required salary rate. In contrast, the required minimal salary rate decreases with increasing time preference of disutility. This is attributed to the average disutility from work effort being lower for a higher value of $\tilde{\rho}$. The individual will deliver a higher work effort, see also Figure 4.

We summarize that the offered salary rate $\delta$ can act as a selection device for the smaller listed company. Under the assumption that potential job candidates have an identical outside option, the group of individuals satisfying a more restrictive participation constraint is in general more talented, i.e. the individuals exhibit a lower disutility stress $\alpha$, a higher productivity $1 / \tilde{\kappa}$, a lower time preference for consumption $\rho$, and a higher time preference for disutility from work effort $\tilde{\rho}$. Viewing the holdings in the own-company shares $\left(\pi^{S \star}(t)=\lambda^{\star}(t) / \sigma\right)$ as a way of voluntarily linking the pay to performance, our results reflect common practice in executive remuneration. A more talented manager is in general attracted by a lower fixed salary component and a higher performance linked salary component.

\section{Conclusion and Outlook}

We establish a model framework that gives insight into an individual's occupational decision when she can choose between two different positions. She is offered an executive position in smaller listed company where she can affect the company's share price by work effort. Alternatively, she can take up a mid-level management position with a larger company but then forgoes the possibility to affect the other company's share price. We identify conditions for the individual to work for the smaller listed company where the participation constraint is given in terms of the salary differential of the two job alternatives. In particular, we derive the minimal required salary $\delta^{\star}$ that 
needs to be offered by the smaller company to attract the individual and thereby characterize the participation constraint. In general, we find that a more talented individual requires a lower salary to be attracted to the smaller listed company. This salary pattern can be observed in practice, e.g., in the pharmaceutical industry, the IT sector, and the financial industry.

Given that the participation constraint holds, we give explicit solutions for the individual's utility maximizing behavior in terms of the investment strategy $\left(\pi=\left(\pi^{P}, \pi^{S}\right)\right)$, consumption $(k)$, and work effort $(\lambda)$. Overall, our results depend sensibly on her characteristics, work productivity $1 / \kappa$, disutility stress $\alpha$, time preference of consumption $\rho$, and time preference of work effort $\tilde{\rho}$. We demonstrate that an executive with higher work effectiveness (quality) undertakes more work effort, which is associated with a lower minimal required salary $\delta^{\star}$. The main analysis is performed in the log-utility setting. However, we also explore the broader setup of constant relative risk aversion.

A future development of this work is to extend the semi-static game between the individual and the smaller listed company to a stochastic differential game. The aim of the company is then to maximize share holder value. The additional control available to the company is the quantity of share-based payments granted to the individual that affect her holdings in the company's shares. The stochastic differential game can then be investigated for equilibria. This setup is likely to provide more insight into the design of optimal share-based payments.

\section{Appendix}

Proof of Theorem 3.5. Define the performance functional of our optimal investment, consumption and control decision again by (27). Our candidates are optimal if we have

$$
\begin{aligned}
& J^{\prime}\left(t, v ; \pi^{\star}, \lambda^{\star}, k^{\star}\right)=\Phi(t, v) \text { and } \\
& J^{\prime}(t, v ; \pi, \lambda, k) \leq \Phi(t, v), \text { for all }(\pi, \lambda, k) \in A_{\gamma}^{\prime}(t, v) .
\end{aligned}
$$


Let $u \in A_{\gamma}^{\prime}(t, v)$. Since $\Phi \in C^{1,2}$, we obtain by Ito's formula:

$$
\begin{gathered}
\Phi\left(T, V_{T}^{u}\right)-\int_{t}^{T} \kappa\left(V_{s}^{u}\right)^{1-\gamma} \frac{\lambda_{s}^{\alpha}}{\alpha} \mathrm{d} s+\int_{t}^{T} \frac{\left(V_{s}^{u} k\right)^{1-\gamma}}{1-\gamma} \mathrm{d} s=\Phi(t, v)+ \\
\int_{t}^{T}\left\{\Phi_{t}\left(s, V_{s}^{u}\right)+\Phi_{v}\left(s, V_{s}^{u}\right) V_{s}^{u}\left[r+\pi_{s}^{S} \lambda_{s} \sigma+\left(\pi_{s}^{P}+\beta \pi_{s}^{S}\right) \lambda^{P} \sigma^{P}+\delta-k_{s}\right]\right. \\
+1 / 2 \Phi_{v v}\left(s, V_{s}^{u}\right)\left(V_{s}^{u}\right)^{2}\left[\left(\pi_{s}^{P}+\beta \pi_{s}^{S}\right)^{2}\left(\sigma^{P}\right)^{2}+\left(\pi_{s}^{S} \sigma\right)^{2}\right] \\
\left.-\kappa\left(V_{s}^{u}\right)^{1-\gamma} \frac{\lambda_{s}^{\alpha}}{\alpha} \mathrm{d} s+\frac{\left(V_{s}^{u} k\right)^{1-\gamma}}{1-\gamma}\right\} \\
+\int_{t}^{T} \Phi_{v}\left(s, V_{s}^{u}\right) V_{s}^{u}\left(\pi_{s}^{P}+\beta \pi_{s}^{S}\right) \sigma^{P} \mathrm{~d} W_{s}^{P}+\int_{t}^{T} \Phi_{v}\left(s, V_{s}^{u}\right) V_{s}^{u} \pi_{s}^{S} \sigma \mathrm{d} W_{s} .
\end{gathered}
$$

For the optimality candidates given in (19), the local martingale component in (55) disappears. A sufficient condition to verify this is the square integrability condition

$$
\mathbb{E}\left[\int_{t}^{T}\left(\Phi_{v}\left(s, V_{s}^{u^{\star}}\right) V_{s}^{u^{\star}}\right)^{2}\left(\left[\pi_{s}^{P^{\star}}+\beta \pi_{s}^{S^{\star}}\right]^{2}\left(\sigma^{P}\right)^{2}+\left[\pi_{s}^{S^{\star}} \sigma\right]^{2}\right)\right] \mathrm{d} s<\infty
$$

Now substituting the candidates from (40) - (44) yields

$$
\begin{aligned}
\left(\Phi_{v}\left(s, V_{s}^{u^{\star}}\right) V_{s}^{u^{\star}}\right)^{2}\left(\left[\pi_{s}^{P^{\star}}\right.\right. & \left.\left.+\beta \pi_{s}^{S^{\star}}\right]^{2}\left(\sigma^{P}\right)^{2}+\left[\pi_{s}^{S^{\star}} \sigma\right]^{2}\right) \\
& =\frac{\left(V_{s}^{u^{\star}}\right)^{2(1-\gamma)} f(s)^{2}}{\gamma^{2}}\left[\left(\lambda^{P}\right)^{2}+\left(\frac{1}{\kappa \gamma} f(s)\right)^{\frac{1}{\gamma}}\right] .
\end{aligned}
$$

The RHS of $(* *)$ is $\left(V_{s}^{u^{\star}}\right)^{2(1-\gamma)}$ times a deterministic and continuous function on the compact set $[0, T]$. The deterministic part is uniformly bounded. Therefore it is sufficient to focus on the stochastic component: $V_{s}^{u^{\star}}$ satisfies the wealth equation

$$
\begin{aligned}
\mathrm{d} V_{t}^{u^{\star}}=V_{t}^{u^{\star}}\left[r \mathrm{~d} t+\frac{\lambda_{P}^{2}}{\gamma} \mathrm{d} t+\frac{\left(\lambda^{\star}\left(t, V_{t}^{u^{\star}}\right)\right)^{2}}{\gamma} \mathrm{d} t\right. & -(f(t))^{-\frac{1}{\gamma}} \mathrm{d} t+\delta \mathrm{d} t \\
& \left.+\frac{\lambda_{P}}{\gamma} \mathrm{d} W_{t}^{P}+\frac{\lambda^{\star}\left(t, V_{t}^{u^{\star}}\right)}{\gamma} \mathrm{d} W_{t}\right],
\end{aligned}
$$

for which we have substituted the optimality candidates (40) in the original wealth equation. Recalling that $\lambda^{\star}(t, v)$ is a deterministic function in $t$ and 
further does not depend on $v$ and that $f(t)$ is a deterministic function as well, we see that $V_{t}^{u^{\star}}$ follows a log-normal distribution for all $t \geq 0$ with parameters being uniformly bounded for all $t \in[0, T]$. Since all moments of a lognormally distributed random variable exist, we have proven $(*)$. Furthermore $\Phi$ satisfies the HJB equation (8), i.e. for $u=u^{\star}=\left(\pi^{P^{\star}}, \pi^{S^{\star}}, \lambda^{\star}, k^{\star}\right)$, the choice (16) of the disutility function and the choice (15) of the consumpion rate we have:

$$
\begin{aligned}
& \Phi_{t}\left(s, V_{s}^{u^{\star}}\right)+\Phi_{v}\left(s, V_{s}^{u^{\star}}\right) V_{s}^{u^{\star}}\left[r+\pi_{s}^{S^{\star}} \lambda_{s}^{\star} \sigma+\left(\pi_{s}^{P^{\star}}+\beta \pi_{s}^{S^{\star}}\right) \lambda^{P} \sigma^{P}+\delta-k_{s}^{\star}\right] \\
& +1 / 2 \Phi_{v v}\left(s, V_{s}^{u^{\star}}\right)\left(V_{s}^{u^{\star}}\right)^{2}\left[\left(\pi_{u}^{P^{\star}}+\beta \pi_{u}^{S^{\star}}\right)^{2}\left(\sigma^{P}\right)^{2}+\left(\pi_{s}^{S^{\star}} \sigma\right)^{2}\right] \\
& -\kappa\left(V_{s}^{u^{\star}}\right)^{1-\gamma} \frac{\left(\lambda_{s}^{\star}\right)^{\alpha}}{\alpha}+\frac{\left(V_{s}^{u^{\star}} k^{\star}\right)^{1-\gamma}}{1-\gamma}=0 .
\end{aligned}
$$

Then, for $u=u^{\star}$, the expectation of equation (55) using $\Phi(T, v)=v^{1-\gamma} /(1-$ $\gamma)$ is:

$$
\begin{aligned}
& \mathbb{E}^{t, v}\left[\frac{\left(V_{T}^{u^{\star}}\right)^{1-\gamma}}{1-\gamma}\right]-\mathbb{E}^{t, v}\left[\int_{t}^{T} \kappa\left(V_{s}^{u^{\star}}\right)^{1-\gamma} \frac{\left(\lambda_{s}^{\star}\right)^{\alpha}}{\alpha} \mathrm{d} s\right]+\mathbb{E}^{t, v}\left[\int_{t}^{T} \frac{\left(V_{s}^{u^{\star}} k^{\star}\right)^{1-\gamma}}{1-\gamma} \mathrm{d} s\right] \\
& =J^{\prime}\left(t, v ; \pi^{\star}, \lambda^{\star}, k^{\star}\right)=\Phi(t, v) .
\end{aligned}
$$

The optimality of our candidates is finally shown if we have for all $(\pi, \lambda, k) \in$ $A_{\gamma}^{\prime}(t, v)$ :

$$
\begin{aligned}
& \mathbb{E}^{t, v}\left[\frac{\left(V_{T}^{u}\right)^{1-\gamma}}{1-\gamma}\right]-\mathbb{E}^{t, v}\left[\int_{t}^{T} \kappa\left(V_{s}^{u}\right)^{1-\gamma} \frac{\left(\lambda_{s}\right)^{\alpha}}{\alpha} \mathrm{d} s\right]+\mathbb{E}^{t, v}\left[\int_{t}^{T} \frac{\left(V_{s}^{u} k\right)^{1-\gamma}}{1-\gamma} \mathrm{d} s\right] \\
& =J^{\prime}(t, v ; \pi, \lambda, k) \leq \Phi(t, v) .
\end{aligned}
$$

Also, since $\Phi$ satisfies the HJB equation (8), we get for all $(\pi, \lambda, k) \in A_{\gamma}^{\prime}(t, v)$ :

$$
\begin{aligned}
& \Phi_{t}\left(s, V_{s}^{u}\right)+\Phi_{v}\left(s, V_{s}^{u}\right) V_{s}^{u}\left[r+\pi_{s}^{S} \lambda_{s} \sigma+\left(\pi_{s}^{P}+\beta \pi_{s}^{P}\right) \lambda^{P} \sigma^{P}+\delta-k_{s}\right] \\
& \quad+1 / 2 \Phi_{v v}\left(s, V_{s}^{u}\right)\left(V_{s}^{u}\right)^{2}\left[\left(\pi_{u}^{P}+\beta \pi_{u}^{S}\right)^{2}\left(\sigma^{P}\right)^{2}+\left(\pi_{s}^{S^{\star}} \sigma\right)^{2}\right] \\
& \quad-\kappa\left(V_{s}^{u}\right)^{1-\gamma} \frac{\left(\lambda_{s}\right)^{\alpha}}{\alpha}+\frac{\left(V_{s}^{u} k\right)^{1-\gamma}}{1-\gamma} \leq 0 .
\end{aligned}
$$


Substituting this in $(55)$, recalling that $\Phi_{v}(t, v)=f(t) v^{-\gamma}$, we get:

$$
\begin{aligned}
& \Phi\left(T, V_{T}^{u}\right)-\int_{t}^{T} \kappa\left(V_{s}^{u}\right)^{1-\gamma} \frac{\lambda_{s}^{\alpha}}{\alpha} \mathrm{d} s+\int_{t}^{T} \frac{\left(V_{s}^{u} k\right)^{1-\gamma}}{1-\gamma} \mathrm{d} s \leq \Phi(t, v) \\
& +\underbrace{\int_{t}^{T}\left(V_{s}^{u}\right)^{1-\gamma} f(s)\left(\pi_{s}^{P}+\beta \pi_{s}^{S}\right) \sigma^{P} \mathrm{~d} W_{s}^{P}+\int_{t}^{T}\left(V_{s}^{u}\right)^{1-\gamma} f(s) \pi_{s}^{S} \sigma \mathrm{d} W_{s}}_{=: M_{T}^{t}} .
\end{aligned}
$$

To verify equation (56), we impose conditions under which the local martingale $M^{t}$ is a martingale. Recall $\Phi_{v}(t, v)=f(t) v^{-\gamma}$ and calculate the quadratic variation of $M^{t}$

$$
\begin{aligned}
& \left\langle M^{t}\right\rangle_{T}=\int_{t}^{T}\left(V_{s}^{u}\right)^{2(1-\gamma)} f^{2}(s)\left(\left[\pi_{s}^{P}+\beta \pi_{s}^{S}\right]^{2}\left(\sigma^{P}\right)^{2}+\left[\sigma \pi_{s}^{S}\right]^{2}\right) \mathrm{d} s \\
& \leq \frac{1}{2} \sup _{0 \leq s \leq T} f(s)^{2}\left(\int_{t}^{T}\left(V_{s}^{u}\right)^{4(1-\gamma)} \mathrm{d} s+\int_{t}^{T}\left(\left[\pi_{s}^{P}+\beta \pi_{s}^{S}\right]^{2}\left(\sigma^{P}\right)^{2}+\left[\sigma \pi_{s}^{S}\right]^{2}\right)^{2} \mathrm{~d} s\right),
\end{aligned}
$$

where the second line is a straightforward upper bound. We show that $M^{t}$ is a martingale by deriving the integrability of the quadratic variation $\left\langle M^{t}\right\rangle_{T}$. First we use that $f$ is a continuous function on the compact set $[0, T]$ and is uniformly bounded, and thus $\sup _{0 \leq s \leq T} f(s)^{2}$ is finite. We are left to deal with the two expressions in the brackets of (58). The second expression is bounded in expectation by assumption, see (37) in Def. 3.2. In what follows we establish that that the first expression is finite by showing that $\mathbb{E}^{t, v}\left[\left(V_{s}^{u}\right)^{\xi}\right]<\infty$ uniformly, where $\xi=4(1-\gamma)<0$ for $\gamma>1$.

Applying variation of constants, the solution of the wealth equation (4) expressed with respect to the parameter $\lambda$ is

$$
V_{t}^{u}=V_{0}^{u} e^{(r+\delta) t+\int_{0}^{t}\left(\left(\pi_{s}^{P}+\beta \pi_{s}^{S}\right) \lambda^{P} \sigma^{P}+\pi_{s}^{S} \lambda_{s} \sigma-k_{s}\right) \mathrm{d} s} e^{L_{t}-\frac{1}{2}\langle L\rangle_{t}},
$$

where $L_{t}=\int_{0}^{t}\left(\pi_{s}^{P}+\beta \pi_{s}^{S}\right) \sigma^{P} \mathrm{~d} W_{u}^{P}+\int_{0}^{t} \pi_{s}^{S} \sigma \mathrm{d} W_{u}$ and $\langle L\rangle_{t}=\int_{0}^{t}\left(\pi_{s}^{P}+\beta \pi_{s}^{S}\right)^{2}\left(\sigma^{P}\right)^{2}+$ $\left(\pi_{s}^{S} \sigma\right)^{2} \mathrm{~d} s$.

Using this we have

$$
\left(V_{t}^{u}\right)^{\xi}=\left(V_{0}^{u}\right)^{\xi} e^{\xi L_{t}-\frac{1}{2} \xi^{2}\langle L\rangle_{t}} \times e^{\xi\left[\frac{1}{2}(\xi-1)\langle L\rangle_{t}+(r+\delta) t+\int_{0}^{t}\left(\left(\pi_{s}^{P}+\beta \pi_{s}^{S}\right) \lambda^{P} \sigma^{P}+\pi_{s}^{S} \lambda_{s} \sigma-k_{s}\right) d s\right]} .
$$

The second factor is uniformly bounded by a constant, compare the conditions (37), (38) and (39) of Definition 3.2, recalling that $\xi<0$ for $\gamma>1$, and 
keeping in mind that $k_{t} \geq 0, t \leq s \leq T$, by assumption. It remains to prove that the first factor, $Z_{t}:=e^{\xi L_{t}-\frac{1}{2} \xi^{2}\langle L\rangle_{t}} \in L^{2}(P), t \leq u \leq T$, is integrable. However, $Z^{t}$ is strictly positive local martingale since it is the stochastic exponential of the local martingale $\xi L^{t}$. The Novikov condition holds by (37), i.e.: $\mathbb{E}^{t, v}\left(e^{\frac{1}{2} \xi^{2}\left\langle L^{t}\right\rangle_{T}}\right)<\infty$, and hence $Z^{t}$ is a true martingale and $\mathbb{E}^{t, v}\left(Z_{s}^{t}\right)=1$, $t \leq s \leq T$. The local martingale $M^{t}$ is therefore a martingale vanishing in expectation in (57), implying (56) for $u=(\pi, \lambda, k) \in \mathcal{A}_{\gamma}^{\prime}(t, v)$. 


\section{References}

Cadenillas A, Cvitanić J, Zapatero F (2004) Leverage decision and manager compensation with choice of effort and volatility. Journal of Financial Economics 73(1):71-92

Core J, Guay W, Larcker D (2003) Executive equity compensation and incentives: A survey. Economic Policy Review 9:27-50

Desmettre S, Gould J, Szimayer A (2010) Own-company stockholding and work effort preferences of an unconstrained executive. Working Paper available at SSRN: http://ssrn.com/abstract $=1330814$

Holmstrom B (1979) Moral hazard and observability. Bell Journal of Economics 10:74-91

Jensen M, Meckling W (1976) Theory of the firm: Managerial behavior, agency costs and ownership structure. Journal of Financial Economics $3(4): 305-360$

Korn R, Korn E (2001) Option pricing and portfolio optimization. Graduate Studies in Mathematics, Volume 31, American Mathematical Society

Korn R, Kraft H (2008) Continuous-time delegated portfolio management with homogeneous expectations: Can an agency conflict be avoided? Financial Markets and Portfolio Management 22(1):67-90

Murphy K (1999) Executive compensation. Ashenfelter and D. Card, eds., Handbook of labor economics, Vol. 3, Amsterdam, North-Holland.

Ou-Yang H (2003) Optimal contracts in a continuous-time delegated portfolio management problem. Review of Financial Studies 16(1):173-208

Ross S (1973) The economic theory of agency: The principal's problem. American Economic Review 63(2):134-139 


\section{Figures}

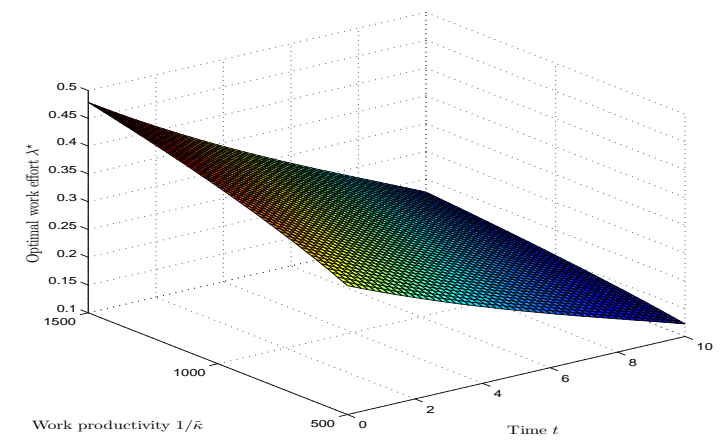

Figure 1: Optimal work effort $\lambda^{\star}$ w.r.t. work productivity $1 / \tilde{\kappa}$ and time $t$ for fixed disutility stress $\alpha=5$, time preferences $\rho=0.10$ and $\tilde{\rho}=-0.10$, $K=1$, base-level work effort $\lambda_{0}=0.10$ and time horizon $T=10$ years.

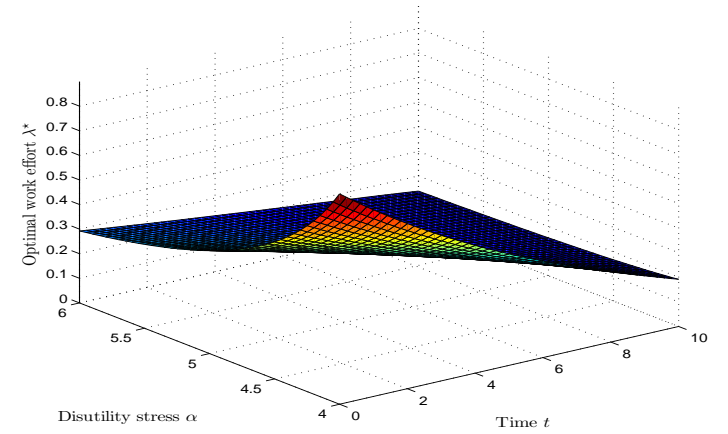

Figure 2: Optimal work effort $\lambda^{\star}$ w.r.t. disutility stress $\alpha$ and time $t$ for fixed work productivity $1 / \tilde{\kappa}=1000$, time preferences $\rho=0.10$ and $\tilde{\rho}=-0.10$, $K=1$, base-level work effort $\lambda_{0}=0.10$ and time horizon $T=10$ years. 


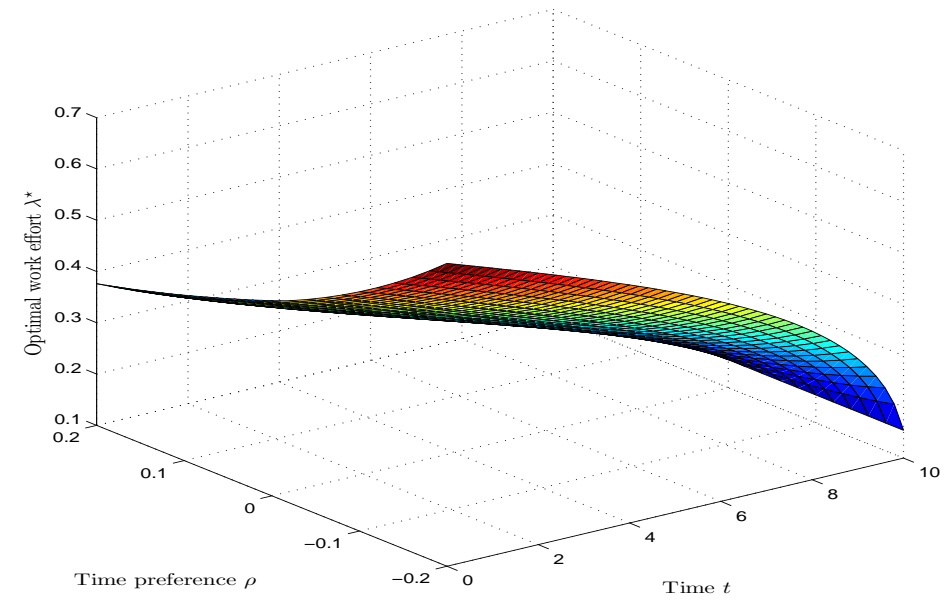

Figure 3: Optimal work effort $\lambda^{\star}$ w.r.t. the time preference of consumption $\rho$ and time $t$ for fixed work productivity $1 / \tilde{\kappa}=1000, \alpha=5$, time preference $\tilde{\rho}=-0.10, K=1$, base-level work effort $\lambda_{0}=0.10$ and time horizon $T=10$ years.

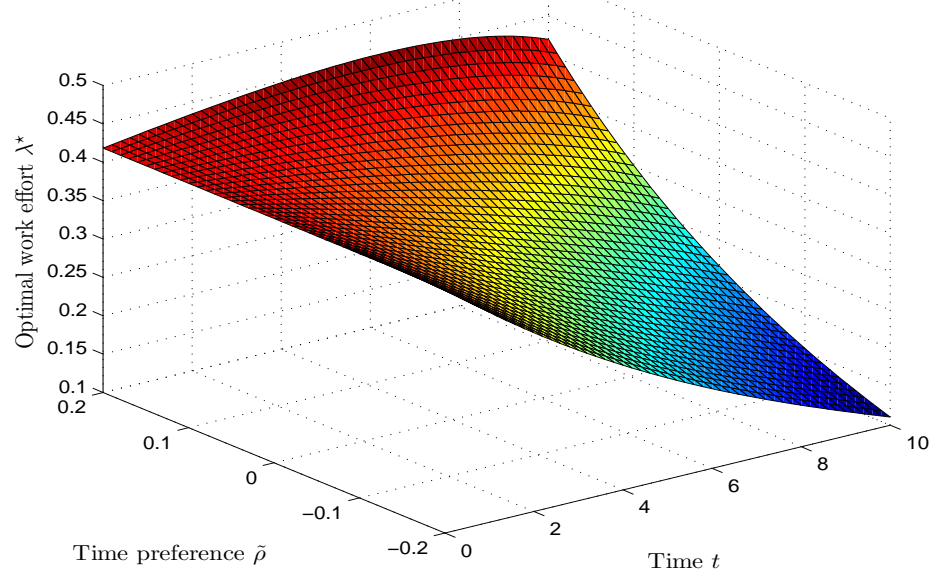

Figure 4: Optimal work effort $\lambda^{\star}$ w.r.t. the time preference of disutility $\tilde{\rho}$ and time $t$ for fixed work productivity $1 / \tilde{\kappa}=1000$, disutility stress $\alpha=5$, time preference $\rho=0.10, K=1$, base-level work effort $\lambda_{0}=0.10$ and time horizon $T=10$ years. 


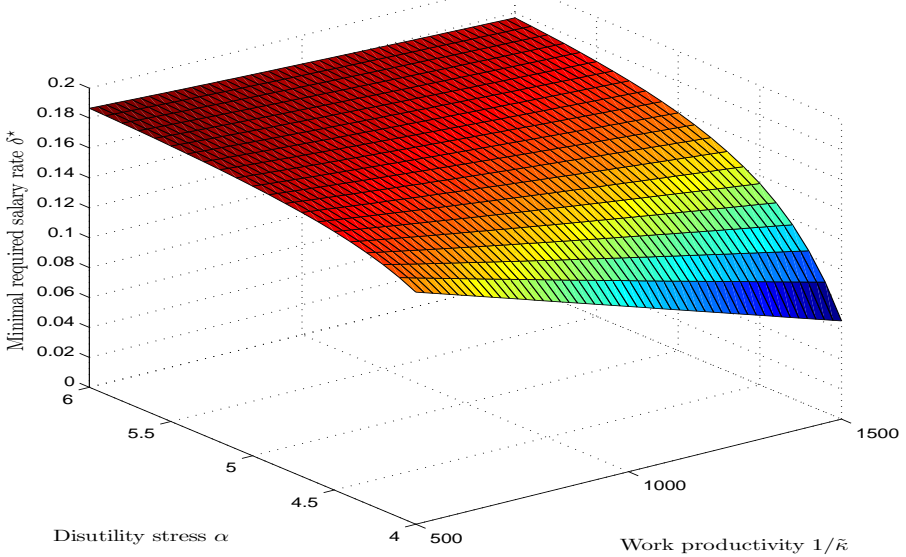

Figure 5: Minimal required salary rate $\delta^{\star}$ w.r.t. disutility stress $\alpha$ and work productivity $1 / \tilde{\kappa}$ for fixed time preferences $\rho=0.10$ and $\tilde{\rho}=-0.10, K=1$, base-level work effort $\lambda_{0}=0.10$, outside salary rate $\widehat{\delta}=0.2$, and time horizon $T=10$ years.

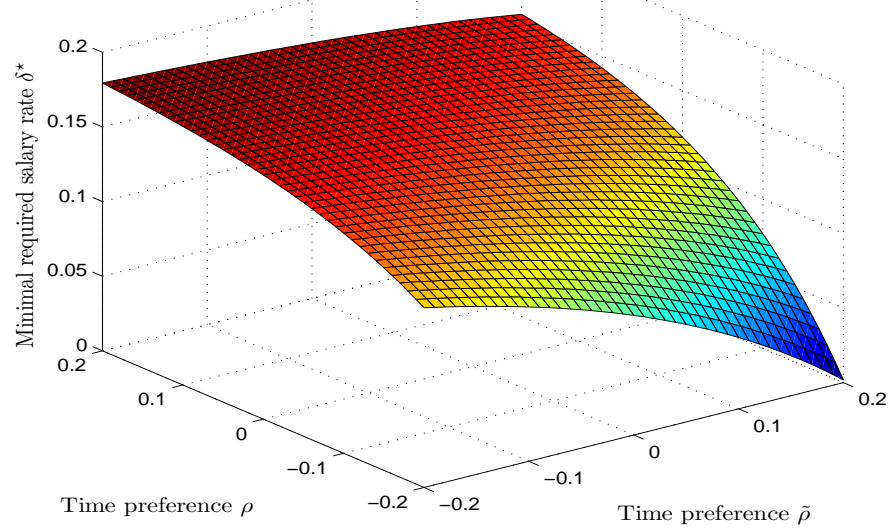

Figure 6: Minimal required salary rate $\delta^{\star}$ w.r.t. the time preferences $\rho$ and $\tilde{\rho}$ for fixed work productivity $1 / \tilde{\kappa}=1000$, disutility stress $\alpha=5, K=1$, base-level work effort $\lambda_{0}=0.10$ and time horizon $T=10$ years. 


\section{Published reports of the Fraunhofer ITWM}

The PDF-files of the following reports are available under:

\section{www.itwm.fraunhofer.de/de/ zentral_berichte/berichte}

1. D. Hietel, K. Steiner, J. Struckmeier A Finite - Volume Particle Method for Compressible Flows (19 pages, 1998)

2. M. Feldmann, S. Seibold

Damage Diagnosis of Rotors: Application of Hilbert Transform and Multi-Hypothesis Testing

Keywords: Hilbert transform, damage diagnosis,

Kalman filtering, non-linear dynamics

(23 pages, 1998)

3. Y. Ben-Haim, S. Seibold

Robust Reliability of Diagnostic MultiHypothesis Algorithms: Application to Rotating Machinery

Keywords: Robust reliability, convex models, Kalman filtering, multi-hypothesis diagnosis, rotating machinery, crack diagnosis

(24 pages, 1998)

\section{F.-Th. Lentes, N. Siedow}

Three-dimensional Radiative Heat Transfer in Glass Cooling Processes

(23 pages, 1998)

5. A. Klar, R. Wegener

A hierarchy of models for multilane vehicular traffic

Part I: Modeling

(23 pages, 1998)

Part II: Numerical and stochastic investigations (17 pages, 1998)

\section{A. Klar, N. Siedow}

Boundary Layers and Domain Decomposition for Radiative Heat Transfer and Diffusion Equations: Applications to Glass Manufacturing Processes

(24 pages, 1998)

7. I. Choquet

Heterogeneous catalysis modelling and numerical simulation in rarified gas flows Part l: Coverage locally at equilibrium (24 pages, 1998)

8. J. Ohser, B. Steinbach, C. Lang Efficient Texture Analysis of Binary Images (17 pages, 1998)

9. J. Orlik

Homogenization for viscoelasticity of the integral type with aging and shrinkage (20 pages, 1998)

10. J. Mohring

Helmholtz Resonators with Large Aperture (21 pages, 1998)
11. H. W. Hamacher, A. Schöbel On Center Cycles in Grid Graphs (15 pages, 1998)

12. H. W. Hamacher, K.-H. Küfer Inverse radiation therapy planning a multiple objective optimisation approach (14 pages, 1999)

13. C. Lang, J. Ohser, R. Hilfer On the Analysis of Spatial Binary Images (20 pages, 1999)

14. M. Junk

On the Construction of Discrete Equilibrium Distributions for Kinetic Schemes (24 pages, 1999)

15. M. Junk, S. V. Raghurame Rao

A new discrete velocity method for NavierStokes equations

(20 pages, 1999)

16. H. Neunzert

Mathematics as a Key to Key Technologies (39 pages (4 PDF-Files), 1999)

17. J. Ohser, K. Sandau

Considerations about the Estimation of the Size Distribution in Wicksell's Corpuscle Problem

(18 pages, 1999)

18. E. Carrizosa, H. W. Hamacher, R. Klein, S. Nickel

Solving nonconvex planar location problems by finite dominating sets

Keywords: Continuous Location, Polyhedral Gauges, Finite Dominating Sets, Approximation, Sandwich Algorithm, Greedy Algorithm

(19 pages, 2000)

\section{A. Becker}

A Review on Image Distortion Measures Keywords: Distortion measure, human visual system (26 pages, 2000)

20. H. W. Hamacher, M. Labbé, S. Nickel, T. Sonneborn

Polyhedral Properties of the Uncapacitated Multiple Allocation Hub Location Problem Keywords: integer programming, hub location, facility location, valid inequalities, facets, branch and cut (21 pages, 2000)

21. H. W. Hamacher, A. Schöbel

Design of Zone Tariff Systems in Public Transportation

(30 pages, 2001)

22. D. Hietel, M. Junk, R. Keck, D. Teleaga The Finite-Volume-Particle Method for Conservation Laws (16 pages, 2001)

23. T. Bender, H. Hennes, J. Kalcsics, M. T. Melo, S. Nickel

Location Software and Interface with GIS and Supply Chain Management Keywords: facility location, software development, geographical information systems, supply chain management

(48 pages, 2001)
24. H. W. Hamacher, S. A. Tjandra Mathematical Modelling of Evacuation Problems: A State of Art (44 pages, 2001)

25. J. Kuhnert, S. Tiwari

Grid free method for solving the Poisson equation

Keywords: Poisson equation, Least squares method, Grid free method

(19 pages, 2001)

26. T. Götz, H. Rave, D. Reinel-Bitzer, K. Steiner, $\mathrm{H}$. Tiemeier

Simulation of the fiber spinning process Keywords: Melt spinning, fiber model, Lattice Boltzmann, CFD

(19 pages, 2001)

\section{A. Zemitis}

On interaction of a liquid film with an obstacle Keywords: impinging jets, liquid film, models, numerical solution, shape

22 pages, 2001)

\section{I. Ginzburg, K. Steiner}

Free surface lattice-Boltzmann method to model the filling of expanding cavities by Bingham Fluids

Keywords: Generalized LBE, free-surface phenomena interface boundary conditions, filling processes, Bing ham viscoplastic model, regularized models

(22 pages, 2001)

\section{H. Neunzert}

"Denn nichts ist für den Menschen als Menschen etwas wert, was er nicht mit Leidenschaft tun kann

Vortrag anlässlich der Verleihung des Akademiepreises des Landes RheinlandPfalz am 21.11.2001

Keywords: Lehre, Forschung, angewandte Mathematik, Mehrskalenanalyse, Strömungsmechanik (18 pages, 2001)

30. J. Kuhnert, S. Tiwari

Finite pointset method based on the projection method for simulations of the incompressible Navier-Stokes equations

Keywords: Incompressible Navier-Stokes equations, Meshfree method, Projection method, Particle scheme, Least squares approximation

AMS subject classification: 76D05, 76M28

(25 pages, 2001)

31. R. Korn, M. Krekel

Optimal Portfolios with Fixed Consumption or Income Streams

Keywords: Portfolio optimisation, stochastic control, HJB equation, discretisation of control problems (23 pages, 2002)

32. M. Krekel

Optimal portfolios with a loan dependent credit spread

Keywords: Portfolio optimisation, stochastic control, HJB equation, credit spread, log utility, power utility, non-linear wealth dynamics

(25 pages, 2002)

33. J. Ohser, W. Nagel, K. Schladitz

The Euler number of discretized sets - on the choice of adjacency in homogeneous lattices Keywords: image analysis, Euler number, neighborhod relationships, cuboidal lattice

(32 pages, 2002) 
34. I. Ginzburg, K. Steiner

Lattice Boltzmann Model for Free-Surface flow and Its Application to Filling Process in Casting

Keywords: Lattice Boltzmann models; free-surface phenomena; interface boundary conditions; filling processes; injection molding; volume of fluid method; interface boundary conditions; advection-schemes; upwind-schemes

(54 pages, 2002)

35. M. Günther, A. Klar, T. Materne, R. Wegener

Multivalued fundamental diagrams and stop and go waves for continuum traffic equations Keywords: traffic flow, macroscopic equations, kinetic derivation, multivalued fundamental diagram, stop and go waves, phase transitions

(25 pages, 2002)

36. S. Feldmann, P. Lang, D. Prätzel-Wolters Parameter influence on the zeros of network determinants

Keywords: Networks, Equicofactor matrix polynomials, Realization theory, Matrix perturbation theory

(30 pages, 2002)

\section{K. Koch, J. Ohser, K. Schladitz} Spectral theory for random closed sets and estimating the covariance via frequency space

Keywords: Random set, Bartlett spectrum, fast Fourier transform, power spectrum

(28 pages, 2002)

\section{D. d'Humières, I. Ginzburg}

Multi-reflection boundary conditions for lattice Boltzmann models

Keywords: lattice Boltzmann equation, boudary condistions, bounce-back rule, Navier-Stokes equation

(72 pages, 2002)

\section{R. Korn}

\section{Elementare Finanzmathematik}

Keywords: Finanzmathematik, Aktien, Optionen, Portfolio-Optimierung, Börse, Lehrerweiterbildung, Mathematikunterricht

(98 pages, 2002)

40. J. Kallrath, M. C. Müller, S. Nickel

Batch Presorting Problems:

Models and Complexity Results

Keywords: Complexity theory, Integer programming,

Assigment, Logistics

(19 pages, 2002)

\section{J. Linn}

On the frame-invariant description of the phase space of the Folgar-Tucker equation Key words: fiber orientation, Folgar-Tucker equation, injection molding

(5 pages, 2003)

\section{T. Hanne, S. Nickel}

A Multi-Objective Evolutionary Algorithm for Scheduling and Inspection Planning in Software Development Projects

Key words: multiple objective programming, project management and scheduling, software development, evolutionary algorithms, efficient set

(29 pages, 2003)

43. T. Bortfeld, K.-H. Küfer, M. Monz,

A. Scherrer, C. Thieke, H. Trinkaus

Intensity-Modulated Radiotherapy - A Large Scale Multi-Criteria Programming Problem
Keywords: multiple criteria optimization, representative systems of Pareto solutions, adaptive triangulation, clustering and disaggregation techniques, visualization of Pareto solutions, medical physics, external beam radiotherapy planning, intensity modulated radiotherapy (31 pages, 2003)

\section{T. Halfmann, T. Wichmann}

Overview of Symbolic Methods in Industrial Analog Circuit Design

Keywords: $C A D$, automated analog circuit design, sym bolic analysis, computer algebra, behavioral modeling, system simulation, circuit sizing, macro modeling, differential-algebraic equations, index

(17 pages, 2003)

\section{S. E. Mikhailov, J. Orlik}

Asymptotic Homogenisation in Strength and Fatigue Durability Analysis of Composites

Keywords: multiscale structures, asymptotic homogenization, strength, fatigue, singularity, non-local conditions

(14 pages, 2003)

46. P. Domínguez-Marín, P. Hansen, N. Mladenovi'c , S. Nickel

Heuristic Procedures for Solving the Discrete Ordered Median Problem

Keywords: genetic algorithms, variable neighborhood search, discrete facility location

(31 pages, 2003)

47. N. Boland, P. Domínguez-Marín, S. Nickel, J. Puerto

Exact Procedures for Solving the Discrete Ordered Median Problem

Keywords: discrete location, Integer programming

(41 pages, 2003)

48. S. Feldmann, P. Lang

Padé-like reduction of stable discrete linear systems preserving their stability Keywords: Discrete linear systems, model reduction, stability, Hankel matrix, Stein equation

(16 pages, 2003)

49. J. Kallrath, S. Nickel

A Polynomial Case of the Batch Presorting Problem

Keywords: batch presorting problem, online optimization, competetive analysis, polynomial algorithms, logistics (17 pages, 2003)

\section{T. Hanne, H. L. Trinkaus}

knowCube for MCDM -

Visual and Interactive Support for Multicriteria Decision Making

Key words: Multicriteria decision making, knowledge management, decision support systems, visual interfaces, interactive navigation, real-life applications. (26 pages, 2003)

51. O. lliev, V. Laptev

On Numerical Simulation of Flow Through Oil Filters

Keywords: oil filters, coupled flow in plain and porous media, Navier-Stokes, Brinkman, numerical simulation (8 pages, 2003)

52. W. Dörfler, O. Iliev, D. Stoyanov, D. Vassileva On a Multigrid Adaptive Refinement Solver for Saturated Non-Newtonian Flow in Porous Media

Keywords: Nonlinear multigrid, adaptive refinement, non-Newtonian flow in porous media

(17 pages, 2003)
53. S. Kruse

On the Pricing of Forward Starting Options under Stochastic Volatility

Keywords: Option pricing, forward starting options, Heston model, stochastic volatility, cliquet options (11 pages, 2003)

54. O. Iliev, D. Stoyanov

Multigrid - adaptive local refinement solver for incompressible flows

Keywords: Navier-Stokes equations, incompressible flow projection-type splitting, SIMPLE, multigrid methods, adaptive local refinement, lid-driven flow in a cavity (37 pages, 2003)

\section{V. Starikovicius}

The multiphase flow and heat transfer in porous media

Keywords: Two-phase flow in porous media, various formulations, global pressure, multiphase mixture model, numerical simulation

(30 pages, 2003)

\section{P. Lang, A. Sarishvili, A. Wirsen}

Blocked neural networks for knowledge extraction in the software development process Keywords: Blocked Neural Networks, Nonlinear Regression, Knowledge Extraction, Code Inspection (21 pages, 2003)

\section{H. Knaf, P. Lang, S. Zeiser}

Diagnosis aiding in Regulation

Thermography using Fuzzy Logic

Keywords: fuzzy logic, knowledge representation, expert system

(22 pages, 2003)

58. M. T. Melo, S. Nickel, F. Saldanha da Gama Largescale models for dynamic multicommodity capacitated facility location Keywords: supply chain management, strategic planning, dynamic location, modeling (40 pages, 2003)

\section{J. Orlik}

Homogenization for contact problems with periodically rough surfaces

Keywords: asymptotic homogenization, contact problems (28 pages, 2004)

60. A. Scherrer, K.-H. Küfer, M. Monz,

F. Alonso, T. Bortfeld

IMRT planning on adaptive volume structures - a significant advance of computational complexity

Keywords: Intensity-modulated radiation therapy (IMRT), inverse treatment planning, adaptive volume structures, hierarchical clustering, local refinement, adaptive clustering, convex programming, mesh generation, multi-grid methods

(24 pages, 2004)

\section{D. Kehrwald}

Parallel lattice Boltzmann simulation of complex flows

Keywords: Lattice Boltzmann methods, parallel computing, microstructure simulation, virtual material design, pseudo-plastic fluids, liquid composite moulding (12 pages, 2004)

62. O. Iliev, J. Linn, M. Moog, D. Niedziela, V. Starikovicius

On the Performance of Certain Iterative Solvers for Coupled Systems Arising in Discretization of Non-Newtonian Flow Equations 
Keywords: Performance of iterative solvers, Preconditioners, Non-Newtonian flow

(17 pages, 2004)

\section{R. Ciegis, O. Iliev, S. Rief, K. Steiner}

On Modelling and Simulation of Different Regimes for Liquid Polymer Moulding Keywords: Liquid Polymer Moulding, Modelling, Simulation, Infiltration, Front Propagation, non-Newtonian flow in porous media

(43 pages, 2004)

\section{T. Hanne, H. Neu}

Simulating Human Resources in

\section{Software Development Processes}

Keywords: Human resource modeling, software process, productivity, human factors, learning curve

(14 pages, 2004)

\section{O. Iliev, A. Mikelic, P. Popov}

Fluid structure interaction problems in de-

formable porous media: Toward permeability of deformable porous media

Keywords: fluid-structure interaction, deformable porous media, upscaling, linear elasticity, stokes, finite elements

(28 pages, 2004)

66. F. Gaspar, O. Iliev, F. Lisbona, A. Naumovich, P. Vabishchevich

On numerical solution of 1-D poroelasticity equations in a multilayered domain Keywords: poroelasticity, multilayered material, finite volume discretization, MAC type grid

(41 pages, 2004)

67. J. Ohser, K. Schladitz, K. Koch, M. Nöthe Diffraction by image processing and its application in materials science

Keywords: porous microstructure, image analysis, random set, fast Fourier transform, power spectrum, Bartlett spectrum

(13 pages, 2004)

\section{H. Neunzert}

\section{Mathematics as a Technology: Challenges} for the next 10 Years

Keywords: applied mathematics, technology, modelling, simulation, visualization, optimization, glass processing, spinning processes, fiber-fluid interaction, trubulence effects, topological optimization, multicriteria optimiza tion, Uncertainty and Risk, financial mathematics, Malliavin calculus, Monte-Carlo methods, virtual material design, filtration, bio-informatics, system biology

(29 pages, 2004)

69. R. Ewing, O. lliev, R. Lazarov, A. Naumovich On convergence of certain finite difference discretizations for 1D poroelasticity interface problems

Keywords: poroelasticity, multilayered material, finite volume discretizations, MAC type grid, error estimates (26 pages, 2004 )

70. W. Dörfler, O. Iliev, D. Stoyanov, D. Vassileva On Efficient Simulation of Non-Newtonian Flow in Saturated Porous Media with a Multigrid Adaptive Refinement Solver Keywords: Nonlinear multigrid, adaptive renement non-Newtonian in porous media (25 pages, 2004)

\section{J. Kalcsics, S. Nickel, M. Schröde}

Towards a Unified Territory Design Approach - Applications, Algorithms and GIS Integration Keywords: territory desgin, political districting, sales territory alignment, optimization algorithms, Geographical Information Systems

(40 pages, 2005)
72. K. Schladitz, S Peters, D Reinel-Bitzer, A. Wiegmann, J. Ohser

Design of acoustic trim based on geometric modeling and flow simulation for non-woven Keywords: random system of fibers, Poisson line process, flow resistivity, acoustic absorption, Lattice-Boltzmann method, non-woven (21 pages, 2005)

\section{V. Rutka, A. Wiegmann}

Explicit Jump Immersed Interface Method for virtual material design of the effective elastic moduli of composite materials Keywords: virtual material design, explicit jump immersed interface method, effective elastic moduli, composite materials

(22 pages, 2005)

\section{T. Hanne}

Eine Übersicht zum Scheduling von Baustellen Keywords: Projektplanung, Scheduling, Bauplanung, Bauindustrie

(32 pages, 2005)

75. J. Linn

The Folgar-Tucker Model as a Differetial Algebraic System for Fiber Orientation Calculation

Keywords: fiber orientation, Folgar-Tucker model, invariants, algebraic constraints, phase space, trace stability

(15 pages, 2005)

76. M. Speckert, K. Dreßler, H. Mauch, A. Lion, G. J. Wierda

Simulation eines neuartigen Prüfsystems für Achserprobungen durch MKS-Modellierung einschließlich Regelung Keywords: virtual test rig, suspension testing, multibody simulation, modeling hexapod test rig, opti mization of test rig configuration

(20 pages, 2005)

77. K.-H. Küfer, M. Monz, A. Scherrer, P. Süss, F. Alonso, A. S. A. Sultan, Th. Bortfeld,

D. Craft, Chr. Thieke

Multicriteria optimization in intensity modulated radiotherapy planning Keywords: multicriteria optimization, extreme solutions, real-time decision making, adaptive approxima tion schemes, clustering methods, IMRT planning, reverse engineering

(51 pages, 2005)

78. S. Amstutz, H. Andrä

A new algorithm for topology optimization using a level-set method

Keywords: shape optimization, topology optimization topological sensitivity, level-set

(22 pages, 2005)

\section{N. Ettrich}

Generation of surface elevation models for urban drainage simulation

Keywords: Flooding, simulation, urban elevation models, laser scanning

(22 pages, 2005

80. H. Andrä, J. Linn, I. Matei, I. Shklyar, K. Steiner, E. Teichmann

OPTCAST - Entwicklung adäquater Struk turoptimierungsverfahren für Gießereien Technischer Bericht (KURZFASSUNG) Keywords: Topologieoptimierung, Level-Set-Methode Gießprozesssimulation, Gießtechnische Restriktionen, CAE-Kette zur Strukturoptimierung

(77 pages, 2005)
81. N. Marheineke, R. Wegener Fiber Dynamics in Turbulent Flows Part I: General Modeling Framework Keywords: fiber-fluid interaction; Cosserat rod; turbuence modeling: Kolmogorov's energy spectrum; double-velocity correlations; differentiable Gaussian fields (20 pages, 2005)

\section{Part II: Specific Taylor Drag}

Keywords: flexible fibers; $k-\varepsilon$ turbulence model; fiber-turbulence interaction scales; air drag; random Gaussian aerodynamic force; white noise; stochastic differential equations; ARMA process

(18 pages, 2005)

\section{C. H. Lampert, O. Wirjadi}

An Optimal Non-Orthogonal Separation of the Anisotropic Gaussian Convolution Filter Keywords: Anisotropic Gaussian filter, linear filtering, or entation space, $n D$ image processing, separable filters (25 pages, 2005)

83. H. Andrä, D. Stoyanov

Error indicators in the parallel finite element solver for linear elasticity DDFEM Keywords: linear elasticity, finite element method, hierarchical shape functions, domain decom-position, parallel implementation, a posteriori error estimates (21 pages, 2006)

84. M. Schröder, I. Solchenbach Optimization of Transfer Quality in Regional Public Transit

Keywords: public transit, transfer quality, quadratic assignment problem

(16 pages, 2006

85. A. Naumovich, F. J. Gaspar

On a multigrid solver for the three-dimensional Biot poroelasticity system in multilayered domains

Keywords: poroelasticity, interface problem, multigrid, operator-dependent prolongation

(11 pages, 2006)

86. S. Panda, R. Wegener, N. Marheineke Slender Body Theory for the Dynamics of Curved Viscous Fibers

Keywords: curved viscous fibers; fluid dynamics; NavierStokes equations; free boundary value problem; asymptotic expansions; slender body theory

(14 pages, 2006)

87. E. Ivanov, H. Andrä, A. Kudryavtsev Domain Decomposition Approach for Automatic Parallel Generation of Tetrahedral Grids Key words: Grid Generation, Unstructured Grid, Delau nay Triangulation, Parallel Programming, Domain Decomposition, Load Balancing

(18 pages, 2006)

88. S. Tiwari, S. Antonov, D. Hietel, J. Kuhnert, R. Wegener

A Meshfree Method for Simulations of In teractions between Fluids and Flexible Structures

Key words: Meshfree Method, FPM, Fluid Structure Interaction, Sheet of Paper, Dynamical Coupling (16 pages, 2006)

89. R. Ciegis, O. Iliev, V. Starikovicius, K. Steine Numerical Algorithms for Solving Problems of Multiphase Flows in Porous Media Keywords: nonlinear algorithms, finite-volume method software tools, porous media, flows

16 pages, 2006) 
90. D. Niedziela, O. Iliev, A. Latz

On 3D Numerical Simulations of Viscoelastic Fluids

Keywords: non-Newtonian fluids, anisotropic viscosity, integral constitutive equation

(18 pages, 2006)

\section{A. Winterfeld}

Application of general semi-infinite Programming to Lapidary Cutting Problems Keywords: large scale optimization, nonlinear programming, general semi-infinite optimization, design centering, clustering

(26 pages, 2006)

\section{J. Orlik, A. Ostrovska}

Space-Time Finite Element Approximation and Numerical Solution of Hereditary Linear Viscoelasticity Problems

Keywords: hereditary viscoelasticity; kern approximation by interpolation; space-time finite element approximation, stability and a priori estimate

(24 pages, 2006)

93. V. Rutka, A. Wiegmann, H. Andrä EJIIM for Calculation of effective Elastic Moduli in 3D Linear Elasticity

Keywords: Elliptic PDE, linear elasticity, irregular domain, finite differences, fast solvers, effective elastic moduli

(24 pages, 2006)

\section{A. Wiegmann, A. Zemitis}

EJ-HEAT: A Fast Explicit Jump Harmonic Averaging Solver for the Effective Heat Conductivity of Composite Materials Keywords: Stationary heat equation, effective thermal conductivity, explicit jump, discontinuous coefficients, virtual material design, microstructure simulation, EJ-HEAT

(21 pages, 2006)

\section{A. Naumovich}

On a finite volume discretization of the three-dimensional Biot poroelasticity system in multilayered domains

Keywords: Biot poroelasticity system, interface problems, finite volume discretization, finite difference method (21 pages, 2006)

\section{M. Krekel, J. Wenzel}

A unified approach to Credit Default Swaption and Constant Maturity Credit Default Swap valuation

Keywords: LIBOR market model, credit risk, Credit Default Swaption, Constant Maturity Credit Default Swapmethod

(43 pages, 2006)

\section{A. Dreyer}

\section{Interval Methods for Analog Circiuts}

Keywords: interval arithmetic, analog circuits, tolerance analysis, parametric linear systems, frequency response, symbolic analysis, CAD, computer algebra

(36 pages, 2006)

98. N. Weigel, S. Weihe, G. Bitsch, K. Dreßler Usage of Simulation for Design and Optimization of Testing

Keywords: Vehicle test rigs, MBS, control, hydraulics,

testing philosophy

(14 pages, 2006)

99. H. Lang, G. Bitsch, K. Dreßler, M. Speckert Comparison of the solutions of the elastic and elastoplastic boundary value problems
Keywords: Elastic BVP, elastoplastic BVP, variational inequalities, rate-independency, hysteresis, linear kinematic hardening, stop- and play-operator

(21 pages, 2006)

100. M. Speckert, K. Dreßler, H. Mauch MBS Simulation of a hexapod based suspension test rig

Keywords: Test rig, MBS simulation, suspension,

hydraulics, controlling, design optimization

(12 pages, 2006)

101. S. Azizi Sultan, K.-H. Küfer

A dynamic algorithm for beam orientations in multicriteria IMRT planning

Keywords: radiotherapy planning, beam orientation optimization, dynamic approach, evolutionary algorithm, global optimization

(14 pages, 2006)

102. T. Götz, A. Klar, N. Marheineke, R. Wegener A Stochastic Model for the Fiber Lay-down Process in the Nonwoven Production Keywords: fiber dynamics, stochastic Hamiltonian system, stochastic averaging

(17 pages, 2006)

103. Ph. Süss, K.-H. Küfer

Balancing control and simplicity: a variable aggregation method in intensity modulated radiation therapy planning

Keywords: IMRT planning, variable aggregation, clustering methods

(22 pages, 2006)

104. A. Beaudry, G. Laporte, T. Melo, S. Nickel Dynamic transportation of patients in hospitals

Keywords: in-house hospital transportation, dial-a-ride, dynamic mode, tabu search

(37 pages, 2006)

105. Th. Hanne

Applying multiobjective evolutionary algorithms in industrial projects

Keywords: multiobjective evolutionary algorithms, discrete optimization, continuous optimization, electronic circuit design, semi-infinite programming, scheduling (18 pages, 2006)

106. J. Franke, S. Halim

Wild bootstrap tests for comparing signals and images

Keywords: wild bootstrap test, texture classification, textile quality control, defect detection, kernel estimate, nonparametric regression

(13 pages, 2007)

107. Z. Drezner, S. Nickel

Solving the ordered one-median problem in the plane

Keywords: planar location, global optimization, ordered median, big triangle small triangle method, bounds, numerical experiments

(21 pages, 2007)

108. Th. Götz, A. Klar, A. Unterreiter, R. Wegener

Numerical evidance for the non-existing of solutions of the equations desribing rotational fiber spinning

Keywords: rotational fiber spinning, viscous fibers, boundary value problem, existence of solutions (11 pages, 2007)
109. Ph. Süss, K.-H. Küfer

Smooth intensity maps and the BortfeldBoyer sequencer

Keywords: probabilistic analysis, intensity modulated radiotherapy treatment (IMRT), IMRT plan application step-and-shoot sequencing

(8 pages, 2007)

110. E. Ivanov, O. Gluchshenko, H. Andrä, A. Kudryavtsev

Parallel software tool for decomposing and meshing of $3 d$ structures

Keywords: a-priori domain decomposition, unstructured grid, Delaunay mesh generation

(14 pages, 2007)

111. O. lliev, R. Lazarov, J. Willems Numerical study of two-grid preconditioners for 1d elliptic problems with highly oscillating discontinuous coefficients Keywords: two-grid algorithm, oscillating coefficients, preconditioner

(20 pages, 2007)

112. L. Bonilla, T. Götz, A. Klar, N. Marheineke, R. Wegener

Hydrodynamic limit of the Fokker-Planckequation describing fiber lay-down processes

Keywords: stochastic dierential equations, FokkerPlanck equation, asymptotic expansion, Ornstein-

Uhlenbeck process

(17 pages, 2007)

\section{S. Rief}

Modeling and simulation of the pressing section of a paper machine

Keywords: paper machine, computational fluid dynamics, porous media

(41 pages, 2007)

114. R. Ciegis, O. Iliev, Z. Lakdawala

On parallel numerical algorithms for simulating industrial filtration problems

Keywords: Navier-Stokes-Brinkmann equations, finite volume discretization method, SIMPLE, parallel computing, data decomposition method

(24 pages, 2007)

\section{N. Marheineke, R. Wegener}

Dynamics of curved viscous fibers with surface tension

Keywords: Slender body theory, curved viscous bers with surface tension, free boundary value problem (25 pages, 2007)

116. S. Feth, J. Franke, M. Speckert Resampling-Methoden zur mse-Korrektur und Anwendungen in der Betriebsfestigkeit Keywords: Weibull, Bootstrap, Maximum-Likelihood, Betriebsfestigkeit

(16 pages, 2007)

117. H. Knaf

Kernel Fisher discriminant functions - a concise and rigorous introduction

Keywords: wild bootstrap test, texture classification, textile quality control, defect detection, kernel estimate, nonparametric regression

(30 pages, 2007)

118. O. Iliev, I. Rybak

On numerical upscaling for flows in heterogeneous porous media 
Keywords: numerical upscaling heterogeneous porous media, single phase flow, Darcy's law, multiscale problem, effective permeability, multipoint flux approximation, anisotropy

(17 pages, 2007)

\section{O. Iliev, I. Rybak}

On approximation property of multipoint flux approximation method

Keywords: Multipoint flux approximation, finite volume method, elliptic equation, discontinuous tensor coeffi-

cients, anisotropy

(15 pages, 2007)

120. O. Iliev, I. Rybak, J. Willems

On upscaling heat conductivity for a class of industrial problems

Keywords: Multiscale problems, effective heat conductivity, numerical upscaling, domain decomposition

(21 pages, 2007)

121. R. Ewing, O. Iliev, R. Lazarov, I. Rybak On two-level preconditioners for flow in porous media

Keywords: Multiscale problem, Darcy's law, single phase flow, anisotropic heterogeneous porous media, numerical upscaling, multigrid, domain decomposition, efficient preconditioner

(18 pages, 2007)

122. M. Brickenstein, A. Dreyer

POLYBORI: A Gröbner basis framework for Boolean polynomials

Keywords: Gröbner basis, formal verification, Boolean polynomials, algebraic cryptoanalysis, satisfiability

(23 pages, 2007)

\section{O. Wirjad}

Survey of $3 d$ image segmentation methods Keywords: image processing, 3d, image segmentation, binarization

(20 pages, 2007)

\section{S. Zeytun, A. Gupta}

A Comparative Study of the Vasicek and the CIR Model of the Short Rate

Keywords: interest rates, Vasicek model, CIR-model,

calibration, parameter estimation

(17 pages, 2007)

\section{G. Hanselmann, A. Sarishvili}

Heterogeneous redundancy in software quality prediction using a hybrid Bayesian approach

Keywords: reliability prediction, fault prediction, nonhomogeneous poisson process, Bayesian model averaging

(17 pages, 2007)

126. V. Maag, M. Berger, A. Winterfeld, K.-H Küfer

A novel non-linear approach to minimal area rectangular packing

Keywords: rectangular packing, non-overlapping constraints, non-linear optimization, regularization, relaxation

(18 pages, 2007)

127. M. Monz, K.-H. Küfer, T. Bortfeld, C. Thieke Pareto navigation - systematic multi-criteria-based IMRT treatment plan determination

Keywords: convex, interactive multi-objective optimization, intensity modulated radiotherapy planning

(15 pages, 2007)
128. M. Krause A Scherrer

On the role of modeling parameters in IMRT plan optimization

Keywords: intensity-modulated radiotherapy (IMRT) inverse IMRT planning, convex optimization, sensitivity analysis, elasticity, modeling parameters, equivalent uniform dose (EUD)

(18 pages, 2007)

\section{A. Wiegmann}

Computation of the permeability of porous materials from their microstructure by FFFStokes

Keywords: permeability, numerical homogenization

fast Stokes solver

(24 pages, 2007)

130. T. Melo, S. Nickel, F. Saldanha da Gama Facility Location and Supply Chain Management - A comprehensive review

Keywords: facility location, supply chain management network design

(54 pages, 2007)

131. T. Hanne, T. Melo, S. Nickel

Bringing robustness to patient flow management through optimized patient transports in hospitals

Keywords: Dial-a-Ride problem, online problem, case study, tabu search, hospital logistics

(23 pages, 2007)

132. R. Ewing, O. Iliev, R. Lazarov, I. Rybak, J. Willems

An efficient approach for upscaling properties of composite materials with high contrast of coefficients

Keywords: effective heat conductivity, permeability of fractured porous media, numerical upscaling, fibrous insulation materials, metal foams

(16 pages, 2008)

133. S. Gelareh, S. Nickel

New approaches to hub location problems in public transport planning Keywords: integer programming, hub location, transportation, decomposition, heuristic

(25 pages, 2008)

134. G. Thömmes, J. Becker, M. Junk, A. K. Vaikuntam, D. Kehrwald, A. Klar, K. Steiner, A. Wiegmann

A Lattice Boltzmann Method for immiscible multiphase flow simulations using the Level Set Method

Keywords: Lattice Boltzmann method, Level Set method, free surface, multiphase flow (28 pages, 2008

\section{J. Orlik}

Homogenization in elasto-plasticity

Keywords: multiscale structures, asymptotic homogenization, nonlinear energy

(40 pages, 2008)

136. J. Almquist, H. Schmidt, P. Lang, J. Deitmer, M. Jirstrand, D. Prätzel-Wolters, H. Becker

Determination of interaction between MCT1 and CAII via a mathematical and physiological approach

Keywords: mathematical modeling; model reduction: electrophysiology; $\mathrm{pH}$-sensitive microelectrodes; proton antenna

(20 pages, 2008)
137. E. Savenkov, H. Andrä, O. Iliev

An analysis of one regularization approach for solution of pure Neumann problem Keywords: pure Neumann problem, elasticity, regularization, finite element method, condition number (27 pages, 2008)

138. O. Berman, J. Kalcsics, D. Krass, S. Nickel The ordered gradual covering location problem on a network

Keywords: gradual covering, ordered median function, network location

(32 pages, 2008)

139. S. Gelareh, S. Nickel

Multi-period public transport design: A novel model and solution approaches Keywords: Integer programming, hub location, public transport, multi-period planning, heuristics (31 pages, 2008)

140. T. Melo, S. Nickel, F. Saldanha-da-Gama Network design decisions in supply chain planning

Keywords: supply chain design, integer programming models, location models, heuristics

(20 pages, 2008)

141. C. Lautensack, A. Särkkä, J. Freitag K. Schladitz

Anisotropy analysis of pressed point processes

Keywords: estimation of compression, isotropy test nearest neighbour distance, orientation analysis, polar ice, Ripley's K function

(35 pages, 2008)

142. O. Iliev, R. Lazarov, J. Willems

A Graph-Laplacian approach for calculating the effective thermal conductivity of complicated fiber geometries

Keywords: graph laplacian, effective heat conductivity, numerical upscaling, fibrous materials

(14 pages, 2008)

143. J. Linn, T. Stephan, J. Carlsson, R. Bohlin Fast simulation of quasistatic rod deformations for VR applications

Keywords: quasistatic deformations, geometrically exact rod models, variational formulation, energy minimization, finite differences, nonlinear conjugate gradients

(7 pages, 2008)

\section{J. Linn, T. Stephan}

Simulation of quasistatic deformations using discrete rod models

Keywords: quasistatic deformations, geometrically exact rod models, variational formulation, energy minimization, finite differences, nonlinear conjugate gradients

(9 pages, 2008

145. J. Marburger, N. Marheineke, R. Pinnau Adjoint based optimal control using meshless discretizations

Keywords: Mesh-less methods, particle methods, Eulerian-Lagrangian formulation, optimization strategies, adjoint method, hyperbolic equations

(14 pages, 2008

\section{S. Desmettre, J. Gould, A. Szimayer}

Own-company stockholding and work effort preferences of an unconstrained executive Keywords: optimal portfolio choice, executive compensation

(33 pages, 2008) 
147. M. Berger, M. Schröder, K.-H. Küfer A constraint programming approach for the two-dimensional rectangular packing problem with orthogonal orientations

Keywords: rectangular packing, orthogonal orientations non-overlapping constraints, constraint propagation

(13 pages, 2008)

148. K. Schladitz, C. Redenbach, T. Sych, M. Godehardt

Microstructural characterisation of open foams using $3 d$ images

Keywords: virtual material design, image analysis, open foams

(30 pages, 2008)

149. E. Fernández, J. Kalcsics, S. Nickel, R. Ríos-Mercado

A novel territory design model arising in the implementation of the WEEE-Directive Keywords: heuristics, optimization, logistics, recycling (28 pages, 2008)

150. H. Lang, J. Linn

Lagrangian field theory in space-time for geometrically exact Cosserat rods Keywords: Cosserat rods, geometrically exact rods, small strain, large deformation, deformable bodies, Lagrangian field theory, variational calculus (19 pages, 2009)

151. K. Dreßler, M. Speckert, R. Müller, Ch. Weber

Customer loads correlation in truck engineering

Keywords: Customer distribution, safety critical components, quantile estimation, Monte-Carlo methods (11 pages, 2009)

152. H. Lang, K. Dreßler

An improved multiaxial stress-strain correction model for elastic FE postprocessing Keywords: Jiang's model of elastoplasticity, stress-strain correction, parameter identification, automatic differentiation, least-squares optimization, Coleman-Li algorithm

(6 pages, 2009)

153. J. Kalcsics, S. Nickel, M. Schröder

A generic geometric approach to territory design and districting

Keywords: Territory design, districting, combinatorial optimization, heuristics, computational geometry (32 pages, 2009)

154. Th. Fütterer, A. Klar, R. Wegener An energy conserving numerical scheme for the dynamics of hyperelastic rods

Keywords: Cosserat rod, hyperealstic, energy conservation, finite differences

(16 pages, 2009)

155. A. Wiegmann, L. Cheng, E. Glatt, O. Iliev, S. Rief

Design of pleated filters by computer simulations

Keywords: Solid-gas separation, solid-liquid separation, pleated filter, design, simulation

(21 pages, 2009)

156. A. Klar, N. Marheineke, R. Wegener Hierarchy of mathematical models for production processes of technical textiles
Keywords: Fiber-fluid interaction, slender-body theory, turbulence modeling, model reduction, stochastic differential equations, Fokker-Planck equation, asymptotic expansions, parameter identification

(21 pages, 2009)

157. E. Glatt, S. Rief, A. Wiegmann, M. Knefel, E. Wegenke

Structure and pressure drop of real and virtual metal wire meshes

Keywords: metal wire mesh, structure simulation, model calibration, CFD simulation, pressure loss (7 pages, 2009)

\section{S. Kruse, M. Mülle}

Pricing American call options under the assumption of stochastic dividends - An application of the Korn-Rogers model Keywords: option pricing, American options, dividends, dividend discount model, Black-Scholes model (22 pages, 2009)

159. H. Lang, J. Linn, M. Arnold

Multibody dynamics simulation of geometrically exact Cosserat rods

Keywords: flexible multibody dynamics, large deformations, finite rotations, constrained mechanical systems, structural dynamics

(20 pages, 2009)

160. P. Jung, S. Leyendecker, J. Linn, M. Ortiz Discrete Lagrangian mechanics and geometrically exact Cosserat rods

Keywords: special Cosserat rods, Lagrangian mechanics, Noether's theorem, discrete mechanics, frame-indifference, holonomic constraints

(14 pages, 2009)

161. M. Burger, K. Dreßler, A. Marquardt, M. Speckert

Calculating invariant loads for system simulation in vehicle engineering

Keywords: iterative learning control, optimal control

theory, differential algebraic equations(DAEs)

(18 pages, 2009)

162. M. Speckert, N. Ruf, K. Dreßler Undesired drift of multibody models excited by measured accelerations or forces Keywords: multibody simulation, full vehicle model, force-based simulation, drift due to noise (19 pages, 2009)

163. A. Streit, K. Dreßler, M. Speckert, J. Lichter, T. Zenner, P. Bach

Anwendung statistischer Methoden zur Erstellung von Nutzungsprofilen für die Auslegung von Mobilbaggern

Keywords: Nutzungsvielfalt, Kundenbeanspruchung, Bemessungsgrundlagen

(13 pages, 2009)

164. I. Correia, S. Nickel, F. Saldanha-da-Gama Anwendung statistischer Methoden zur Erstellung von Nutzungsprofilen für die Auslegung von Mobilbaggern

Keywords: Capacitated Hub Location, MIP formulations (10 pages, 2009)

165. F. Yaneva, T. Grebe, A. Scherrer

An alternative view on global radiotherapy optimization problems

Keywords: radiotherapy planning, path-connected sublevelsets, modified gradient projection method, improving and feasible directions

(14 pages, 2009)
166. J. I. Serna, M. Monz, K.-H. Küfer, C. Thieke Trade-off bounds and their effect in multicriteria IMRT planning

Keywords: trade-off bounds, multi-criteria optimization, IMRT, Pareto surface

(15 pages, 2009)

167. W. Arne, N. Marheineke, A. Meister, R. Wegener

Numerical analysis of Cosserat rod and string models for viscous jets in rotational spinning processes

Keywords: Rotational spinning process, curved viscous fibers, asymptotic Cosserat models, boundary value problem, existence of numerical solutions

(18 pages, 2009)

168. T. Melo, S. Nickel, F. Saldanha-da-Gama An LP-rounding heuristic to solve a multiperiod facility relocation problem

Keywords: supply chain design, heuristic, linear programming, rounding

(37 pages, 2009)

169. I. Correia, S. Nickel, F. Saldanha-da-Gama Single-allocation hub location problems with capacity choices

Keywords: hub location, capacity decisions, MILP formulations

(27 pages, 2009)

170. S. Acar, K. Natcheva-Acar A guide on the implementation of the Heath-Jarrow-Morton Two-Factor Gaussian Short Rate Model (HJM-G2++)

Keywords: short rate model, two factor Gaussian, G2++, option pricing, calibration

(30 pages, 2009)

171. A. Szimayer, G. Dimitroff, S. Lorenz A parsimonious multi-asset Heston model: calibration and derivative pricing Keywords: Heston model, multi-asset, option pricing, calibration, correlation

(28 pages, 2009)

172. N. Marheineke, R. Wegener Modeling and validation of a stochastic drag for fibers in turbulent flows Keywords: fiber-fluid interactions, long slender fibers, turbulence modelling, aerodynamic drag, dimensional analysis, data interpolation, stochastic partial differential algebraic equation, numerical simulations, experimental validations

(19 pages, 2009)

173. S. Nickel, M. Schröder, J. Steeg Planning for home health care services Keywords: home health care, route planning, metaheuristics, constraint programming

(23 pages, 2009)

174. G. Dimitroff, A. Szimayer, A. Wagner Quanto option pricing in the parsimonious Heston model

Keywords: Heston model, multi asset, quanto options, option pricing

(14 pages, 2009) 174. G. Dimitroff, A. Szimayer, A. Wagner

175. S. Herkt, K. Dreßler, R. Pinnau

Model reduction of nonlinear problems in structural mechanics

Keywords: flexible bodies, FEM, nonlinear model reduc tion, $P O D$

(13 pages, 2009) 
176. M. K. Ahmad, S. Didas, J. Iqbal

Using the Sharp Operator for edge detection and nonlinear diffusion

Keywords: maximal function, sharp function, image processing, edge detection, nonlinear diffusion

(17 pages, 2009)

177. M. Speckert, N. Ruf, K. Dreßler, R. Müller, C. Weber, S. Weihe

Ein neuer Ansatz zur Ermittlung von Erprobungslasten für sicherheitsrelevante Bauteile

Keywords: sicherheitsrelevante Bauteile, Kundenbeanspruchung, Festigkeitsverteilung, Ausfallwahrscheinlichkeit, Konfidenz, statistische Unsicherheit, Sicherheitsfaktoren

(16 pages, 2009)

178. J. Jegorovs

Wave based method: new applicability areas Keywords: Elliptic boundary value problems, inhomogeneous Helmholtz type differential equations in bounded domains, numerical methods, wave based method, uniform B-splines

(10 pages, 2009)

179. H. Lang, M. Arnold Numerical aspects in the dynamic simulation of geometrically exact rods Keywords: Kirchhoff and Cosserat rods, geometrically exact rods, deformable bodies, multibody dynamics, artial differential algebraic equations, method of lines, time integration

(21 pages, 2009)

180. H. Lang

Comparison of quaternionic and rotationfree null space formalisms for multibody dynamics

Keywords: Parametrisation of rotations, differentialalgebraic equations, multibody dynamics, constrained mechanical systems, Lagrangian mechanics

(40 pages, 2010)

181. S. Nickel, F. Saldanha-da-Gama, H.-P. Ziegler Stochastic programming approaches for risk aware supply chain network design problems Keywords: Supply Chain Management, multi-stage stochastic programming, financial decisions, risk (37 pages, 2010)

182. P. Ruckdeschel, N. Horbenko

Robustness properties of estimators in generalized Pareto Models

Keywords: global robustness, local robustness, finite

sample breakdown point, generalized Pareto distribution

(58 pages, 2010)

183. P. Jung, S. Leyendecker, J. Linn, M. Ortiz

A discrete mechanics approach to Cosserat rod theory - Part 1: static equilibria

Keywords: Special Cosserat rods; Lagrangian mechanics; Noether's theorem; discrete mechanics; frameindifference; holonomic constraints; variational formulation

(35 pages, 2010)

184. R. Eymard, G. Printsypar

A proof of convergence of a finite volume scheme for modified steady Richards' equation describing transport processes in the pressing section of a paper machine Keywords: flow in porous media, steady Richards' equation, finite volume methods, convergence of approximate solution

(14 pages, 2010)
185. P. Ruckdeschel

\section{Optimally Robust Kalman Filtering}

Keywords: robustness, Kalman Filter, innovation outlier, additive outlier

(42 pages, 2010)

186. S. Repke, N. Marheineke, R. Pinnau

On adjoint-based optimization of a free surface Stokes flow

Keywords: film casting process, thin films, free surface

Stokes flow, optimal control, Lagrange formalism

(13 pages, 2010)

187. O. Iliev, R. Lazarov, J. Willems

Variational multiscale Finite Element Method for flows in highly porous media

Keywords: numerical upscaling, flow in heterogeneous porous media, Brinkman equations, Darcy's law, subgrid approximation, discontinuous Galerkin mixed FEM

(21 pages, 2010)

\section{S. Desmettre, A. Szimayer}

Work effort, consumption, and portfolio selection: When the occupational choice matters

Keywords: portfolio choice, work effort, consumption, occupational choice

(34 pages, 2010) 